\title{
ENSO-Related Global Ocean Heat Content Variations
}

\author{
QURAN WU \\ State Key Laboratory of Marine Environmental Science, College of Ocean and Earth Sciences, Xiamen University, \\ Xiamen, China \\ XUEBIN ZHANG \\ Centre for Southern Hemisphere Oceans Research, CSIRO Oceans and Atmosphere, Hobart, Australia., Surveying and Spatial \\ Sciences, School of Technology, Environments and Design, University of Tasmania, Hobart, Tasmania, Australia \\ JOHN A. CHURCH \\ Climate Change Research Centre, University of New South Wales, Sydney, New South Wales, Australia \\ JIANYU HU \\ State Key Laboratory of Marine Environmental Science, College of Ocean and Earth Sciences, Xiamen University, \\ Xiamen, China
}

(Manuscript received 15 December 2017, in final form 26 September 2018)

\begin{abstract}
The modulation of the full-depth global integrated ocean heat content (GOHC) by El Niño-Southern Oscillation (ENSO) has been estimated in various studies. However, the quantitative results and the mechanisms at work remain uncertain. Here, a dynamically consistent ocean state estimate is utilized to study the large-scale integrated heat content variations during ENSO events for the global ocean. The full-depth GOHC exhibits a cooling tendency during the peak and decaying phases of El Niño, which is a result of the negative surface heat flux (SHF) anomaly in the tropics $\left(30^{\circ} \mathrm{S}-30^{\circ} \mathrm{N}\right)$, partially offset by the positive SHF anomaly at higher latitudes. The tropical SHF anomaly acts as a lagged response to damp the convergence of oceanic heat transport, which redistributes heat from the extratropics and the subsurface layers $(100-440 \mathrm{~m})$ into the upper tropical oceans $(0-100 \mathrm{~m})$ during the onset and peak of El Niño. These results highlight the global nature of the oceanic heat redistribution during ENSO events, as well as how the redistribution process affects the full-depth GOHC. The meridional heat exchange across $30^{\circ} \mathrm{S}$ and $30^{\circ} \mathrm{N}$ is driven by ocean current anomalies, while multiple processes contribute to the vertical heat exchange across $100 \mathrm{~m}$ simultaneously. Heat advection due to unbalanced mass transport is distinguished from the mass balanced one, with significant contributions from the meridional and zonal overturning cells being identified for the latter in the vertical direction. Results presented here have implications for monitoring the planetary energy budget and evaluating ENSO's global imprints on ocean heat content in different estimates.
\end{abstract}

\section{Introduction}

The ocean plays a critical role in Earth's energy budget due to its large heat capacity. Over $90 \%$ of the energy imbalance at the top of the atmosphere (TOA) is stored in the ocean, rendering the full-depth global integrated ocean heat content (GOHC) a fundamental metric of climate change (Rhein et al. 2013). Recent

Corresponding authors: Xuebin Zhang, xuebin.zhang@csiro.au; Jianyu Hu, hujy@xmu.edu.cn observational and modeling efforts have suggested that internal climate variability has a potential role in modulating the full-depth GOHC on interannual-to-decadal time scales, which complicates the detection and attribution of the anthropogenic climate signal. One welldocumented example is the rapid reduction of the full-depth GOHC after the 1997/98 El Niño event (Willis et al. 2004; Domingues et al. 2008; Balmaseda et al. 2013b; Cheng et al. 2016).

El Niño-Southern Oscillation (ENSO) is the most energetic climate variability on interannual time scales 
(2-5 years). It originates in the tropical Pacific via air-sea coupling, and its impacts are felt globally through the atmospheric teleconnections (e.g., McPhaden et al. 2006). Efforts have been made to establish a statistical relationship between the ENSO index and the GOHC. For example, Roemmich and Gilson (2011) found an anomalous heat loss of the global ocean during El Niño events, and the opposite during La Niña events, based on Argo observations. They suggested that $56 \%$ of the variance in the tendency (time derivative) of the $0-500-\mathrm{m} \mathrm{GOHC}$ can be explained by the Niño-3.4 index [average sea surface temperature (SST) anomaly over $5^{\circ} \mathrm{N}-5^{\circ} \mathrm{S}, 170^{\circ}-120^{\circ} \mathrm{W}$; hereafter N34]. Loeb et al. (2012) reached a similar conclusion using the satellite-measured TOA radiation and found a dominant role of outgoing longwave radiation in that process. In addition, Katsman and van Oldenborgh (2011) found that ENSO plays a role in modulating the GOHC of $0-700 \mathrm{~m}$ on decadal time scales via its impact on the outgoing longwave radiation.

In contrast with the in-phase relationship proposed by Roemmich and Gilson (2011), Trenberth et al. (2014) found that the strongest cooling in the ocean occurs 4-12 months after the peak of El Niño in the Ocean Reanalysis System, version 4 (ORAS4; Balmaseda et al. 2013a), with a magnitude of $0.4 \mathrm{~W} \mathrm{~m}^{-2}$. By comparing the temporally integrated TOA radiation (equivalent to the full-depth GOHC) and the N34 index over 2002-16, Johnson and Birnbaum (2017) showed that the ocean is anomalously warm during El Niño events, whereas the opposite happens during La Niña events, with the correlation between the N34 index and the integrated TOA radiation reaching a maximum of 0.72 at zero lag. This result implies a negative tendency in the full-depth GOHC after the peak of El Niño, consistent with Trenberth et al. (2014).

While the ocean as a whole exhibits anomalous heat gains or losses during ENSO events, substantial heat redistribution occurs in its interior. The strongest heat redistribution is observed in the equatorial Pacific where it is threedimensional in nature. In the zonal direction, heat is redistributed eastward during El Niño events, associated with the zonal migration of the western Pacific warm pool. The importance of this process for the ENSO dynamics is detailed in the advective-reflective paradigm by Picaut et al. (1996, 1997). In the meridional direction, Meinen and McPhaden (2000) and Meinen (2005) found that heat is converged into the equatorial band before the onset of El Niño, but discharged from there to $5^{\circ}-10^{\circ} \mathrm{N}$ and $20^{\circ}-5^{\circ} \mathrm{S}$ during the event, consistent with the recharge oscillator paradigm proposed by Jin (1997). In the vertical direction, heat is redistributed upward in the eastern equatorial Pacific during El Niño events, resulting from changes of the thermocline depth and the equatorial upwelling (Jin and Neelin 1993; Jin and An 1999; Jin et al. 2006; Zhang and McPhaden 2006). Detailed studies regarding the three-dimensional heat redistribution in the equatorial Pacific have been carried out using both observations (e.g., Wang and McPhaden 2000, 2001; Meinen and McPhaden 2001; Meinen 2005) and numerical models (e.g., Lee et al. 2004; Kim et al. 2007; Zhang and McPhaden 2008, 2010). A comprehensive summary of this subject is presented in the review paper by Santoso et al. (2017).

Recent advances in ocean observation and data assimilation have introduced the possibility of exploring ENSO's imprints in a global context. The global Argo array has demonstrated that the ENSO-related heat content anomalies are not confined in the tropical Pacific but rather can reach subtropical and subpolar regions, although their magnitudes are weaker than those in the tropics (Roemmich and Gilson 2011; Johnson and Birnbaum 2017). These heat content anomalies when averaged globally have revealed the existence of vertical heat redistribution in the global ocean (Roemmich and Gilson 2011; Wijffels et al. 2016). Specifically, the global averaged temperature profile is anomalously warm at $0-100 \mathrm{~m}$, but anomalously cool at 100$400 \mathrm{~m}$, during El Niño events. In the meridional direction, a poleward heat transport out of the tropics after the 1997/98 El Niño has been documented in a few studies (Mayer et al. 2014; Willis et al. 2004; Balmaseda et al. 2013b). However, whether or not this is a common feature during ENSO events remains unclear. In ERA-Interim and ORAS4, Mayer et al. (2014) found that during El Niño events, the tropical Pacific heat loss is largely redistributed to the tropical Indian and Atlantic Oceans via surface heat fluxes and changes of the Walker circulation.

The aforementioned ENSO-related vertical heat redistribution has a counterpart on decadal time scales. Previous studies have suggested that during some decades, heat uptake reduces in the surface layer, while it increases in the subsurface. Such internally generated decadal heat redistribution is an important mechanism in explaining the recent "global warming hiatus" (e.g., Meehl et al. 2011; Katsman and van Oldenborgh 2011; England et al. 2014; Chen and Tung 2014).

Although ENSO's impact on ocean heat content has been identified in both its global integral and regional distribution, the mechanisms at work are less well quantified. The existing literature has provided important results on the tropical ENSO dynamics, but these detailed heat balance analyses have barely been applied to study ENSO's impacts at latitudes higher than $20^{\circ}$ or depths below $50 \mathrm{~m}$ or the $20^{\circ} \mathrm{C}$ isotherm. Recent works by Roemmich and Gilson (2011) and Johnson and Birnbaum (2017) do provide a near-global picture of ENSO's imprints on ocean heat content, but they have not quantified roles of different pathways and heat transport processes in it. 
In this study, we make an attempt to fill these gaps by examining the ENSO-related heat content variations and associated heat budget over the global ocean. Such analysis could be done for different spatial scales depending on the choice of the control volume. Here, to study the GOHC changes, we conduct a large-scale heat budget analysis by dividing the global ocean into the tropical and extratropical bands $\left(30^{\circ} \mathrm{S}-30^{\circ} \mathrm{N}\right.$ vs higher latitudes) meridionally and into depth ranges of $0-100 \mathrm{~m}$ and $100-440 \mathrm{~m}$ vertically. This framework is specifically set up to verify and better quantify the global heat exchanges between the tropics and extratropics and between the above two depth layers during ENSO events, which are evidenced by recent studies (e.g., Roemmich and Gilson 2011; Balmaseda et al. 2013b). The ocean deeper than $440 \mathrm{~m}$ has a negligible impact on the interannual variability of the GOHC (see section $3 \mathrm{a}$ ), and thus it will not be discussed here. To examine the meridional transport for global ocean, we look at zonal integrated results in which the zonal redistribution becomes an internal process that cannot be assessed directly. Nevertheless, the zonal redistribution is also important for the ENSO-related heat content variations as suggested in a number of papers (e.g., Picaut et al. 1996, 1997; Meinen and McPhaden 2000, 2001; Lee et al. 2004; Kim et al. 2007; Zhang and McPhaden 2010). Here, we aim to complement those previous studies by investigating the meridional and vertical components that are less known and have no intent to dismiss the significance of the zonal redistribution.

In comparison to classical ENSO studies, our results are integrated over much larger meridional extents (e.g., the $30^{\circ} \mathrm{S}-30^{\circ} \mathrm{N}$ tropical band used here vs $5^{\circ} \mathrm{S}-5^{\circ} \mathrm{N}$ equatorial band used in previous studies) to better fit our global-scale analysis. Therefore, caution must be taken when comparing our results with that from classical ENSO studies. For example, the meridional heat convergence/divergence derived here should not be confused with that of the recharge oscillator theory (Jin 1997), because what Jin (1997) proposed is mainly averaged out in our framework.

Historically, the global-scale heat budget analysis is hindered by two factors. First, observations do not resolve all the heat transport processes (e.g., advection and diffusion) globally and have limited coverage below $2000 \mathrm{~m}$ and in the marginal seas and the polar regions. Second, model results based on data assimilation may not conserve heat internally, and thus caution is required in interpreting them quantitatively. To address these issues, we use the 20-yr simulation from Estimating the Circulation and Climate of the Ocean (ECCO), version 4 (hereafter ECCOv4), which is a novel global ocean reanalysis that is observationally constrained while remaining physically consistent (Forget et al. 2015, 2016). In particular, ECCOv4 has provided all the variables that are necessary for closing the heat budget (section 2b), and the roles of different ocean processes in affecting the heat advection can be diagnosed using the full ocean states from ECCOv4 (section 3c).

This paper is organized as follows. In section 2, a detailed introduction of ECCOv4 is presented, including how the heat budget is formulated, along with analysis methods used in this study. Global and regional integrated heat budget anomalies during ENSO events are quantified in section $3 \mathrm{a}$ and then summarized into a two-dimensional diagram in section 3b. Mechanisms of anomalous heat advection are explored in section $3 \mathrm{c}$ using two different frameworks. In section $3 \mathrm{~d}$, we extend the heat budget analysis to a coupled climate model and compare it with ECCOv4. Finally, a discussion and summary are given in sections 4 and 5, respectively.

\section{Data and methods}

a. $\mathrm{ECCOv} 4$

ECCOv4 is an effort to bring a state-of-the-art ocean general circulation model into consistency with observations by finding an optimal set of control parameters of the model. The ocean model of ECCOv4 is a global setup of the MIT general circulation model (MITgcm; Marshall et al. 1997), with a nominal $1^{\circ}$ resolution horizontally and 50 layers vertically. The initial atmospheric forcing of ECCOv4 is computed using the bulk formula of Large and Yeager (2004) and outputs of ERA-Interim reanalysis (Dee et al. 2011). The atmospheric conditions from ERA-Interim are adjusted along with the initial conditions and subgrid-scale parameters of the model iteratively to bring the model states closer to observations using the adjoint approach (Stammer et al. 2002, 2016). Importantly, all the adjustments are constrained by uncertainties of corresponding variables to prevent themselves from being overadjusted. For example, Stammer et al. (2004) have shown that the air-sea flux adjustments derived from an early version of ECCO are consistent with known deficiencies of its atmospheric forcing outside the boundary current regions. Monthly outputs of ECCOv4 over 1992-2011 are used in this study. Detailed information on the setup of ECCOv4 and how it is optimized to fit observations can be found in Forget et al. (2015).

ECCOv4 has two characteristics that make it well suit the motivation of this study. First, ECCOv4 is optimized to fit the global hydrographic data in the recent 20 years, which matches our aim of conducting a global-scale analysis. Forget et al. (2015) have shown that the simulation of ocean temperature and salinity in ECCOv4 is 

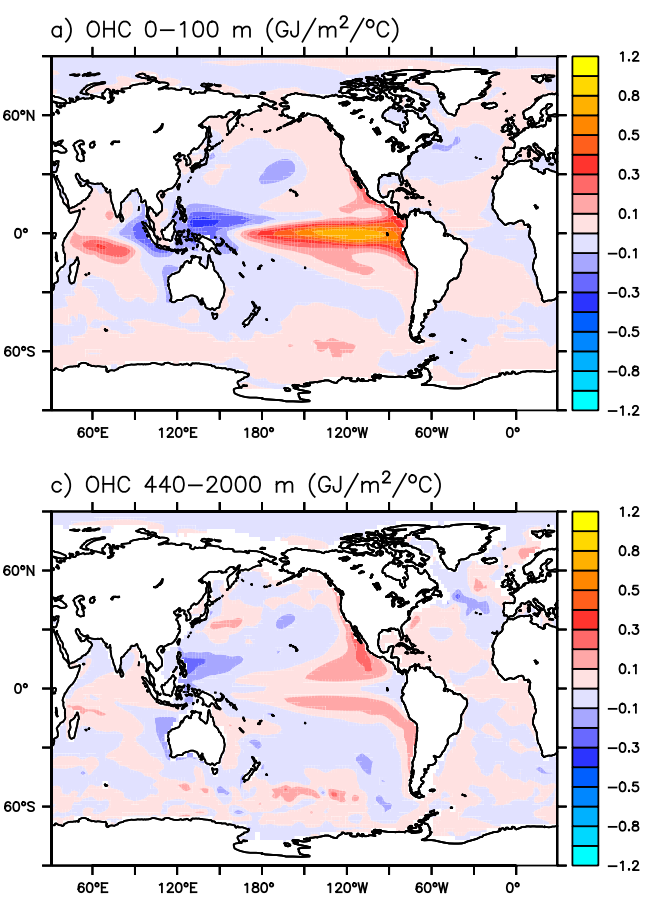
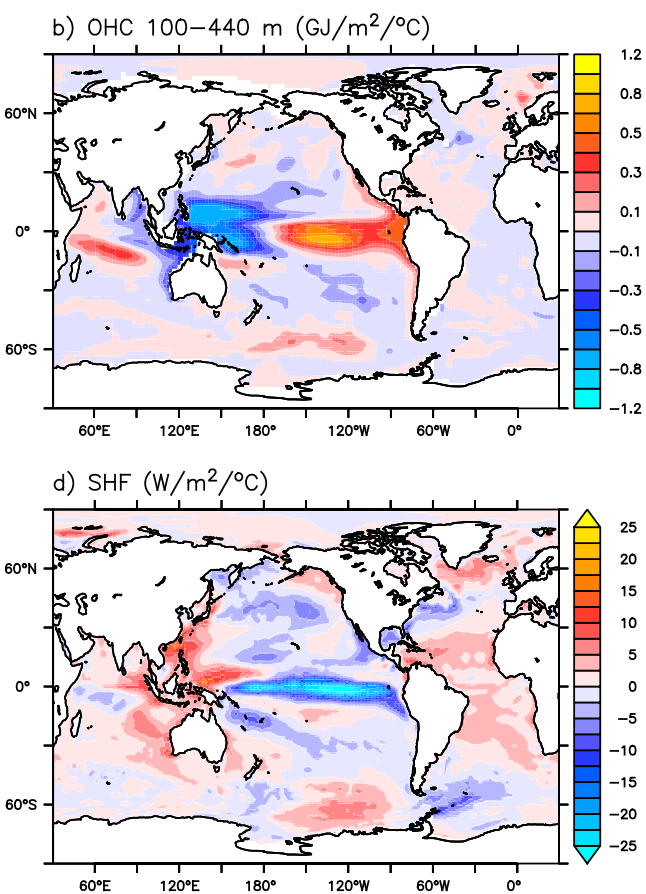

FIG. 1. Regression coefficients of the (a)-(c) OHC and (d) surface heat flux (SHF) against the N34 index at zero $\operatorname{lag}\left(1 \mathrm{GJ}=10^{9} \mathrm{~J}\right)$ from ECCOv4. The OHC is integrated for 0-100 $\mathrm{m}$ in (a), 100-440 $\mathrm{m}$ in (b), and 440-2000 $\mathrm{m}$ in (c), and shown with nonlinear color scales. The global integrals of (a)-(c) are 7.2, -5.2 , and $0.1 \mathrm{ZJ}^{\circ} \mathrm{C}^{-1}$, respectively $\left(1 \mathrm{ZJ}=10^{21} \mathrm{~J}\right)$.

nearly free from large-scale errors when compared with observations. In addition, the ENSO-related ocean heat content anomalies from ECCOv4 exhibit a good agreement with those of the Argo data in Johnson and Birnbaum (2017) for all four depth layers (Figs. 1a-c). The classical east-west tilting mode (Meinen and McPhaden 2000) is also successfully reproduced in ECCOv4 (Figs. 1a,b).

Second, no artificial source/sink is included in ECCOv4's solution, and thus its heat content variations can be fully attributed to well-defined physical processes. This feature of ECCOv4 has led to new insight into the vertical heat transport of the global ocean (Liang et al. 2015, 2017) and improved understanding of heat content variability in the North Atlantic Ocean (Buckley et al. 2014, 2015; Piecuch et al. 2017). The adjusted surface heat flux (SHF) is also an integral part of ECCOv4's solution that is subjected to additional constraints from ocean observations. Liang and Yu (2016) have shown that the SHF in ECCOv4 is in good agreement with the Objectively Analyzed Air-Sea Fluxes (OAFlux; Yu and Weller 2007). During the peak of El Niño, the SHF in ECCOv4 exhibits positive anomalies (the ocean gains heat) in the western Pacific warm pool and negative anomalies in the equatorial central-eastern Pacific (Fig. 1d), consistent with previous studies based on the atmospheric reanalyses (Mayer and Haimberger 2012; Mayer et al. 2013).
The equatorial Pacific Ocean plays a fundamental role in the ENSO dynamics, and the performance of ECCOv4 in replicating key dynamical processes over this area is assessed. ECCOv4 accurately simulates the observed mean distributions of temperature, salinity, and pycnocline strength along the equator from Argo (Fig. 2). While the equatorial zonal currents are successfully resolved in ECCOv4, their magnitudes are weaker by $40 \%-50 \%$ compared to the observations of Johnson et al. (2002) (Fig. 3). Weaker equatorial zonal currents are a common feature of coarse-resolution models (Large et al. 2001), and ECCOv4 with $1^{\circ}$ nominal horizontal resolution is not immune to this deficiency. In addition, the phase relationship between the warm water volume and the N34 index in ECCOv4 is also in good agreement with previous estimates (e.g., Meinen and McPhaden 2000; McPhaden 2012) (results are not shown).

Despite ECCOv4's nominal $1^{\circ}$ grid being thought adequate to resolve large-scale oceanic features that are examined here, it may limit its capability in resolving the effects of small-scale processes appropriately. For example, the model is too coarse to simulate the intense western boundary currents accurately and thus requires additional adjustments of wind stress to compensate this deficiency (Stammer et al. 2004). The coarse-resolution 

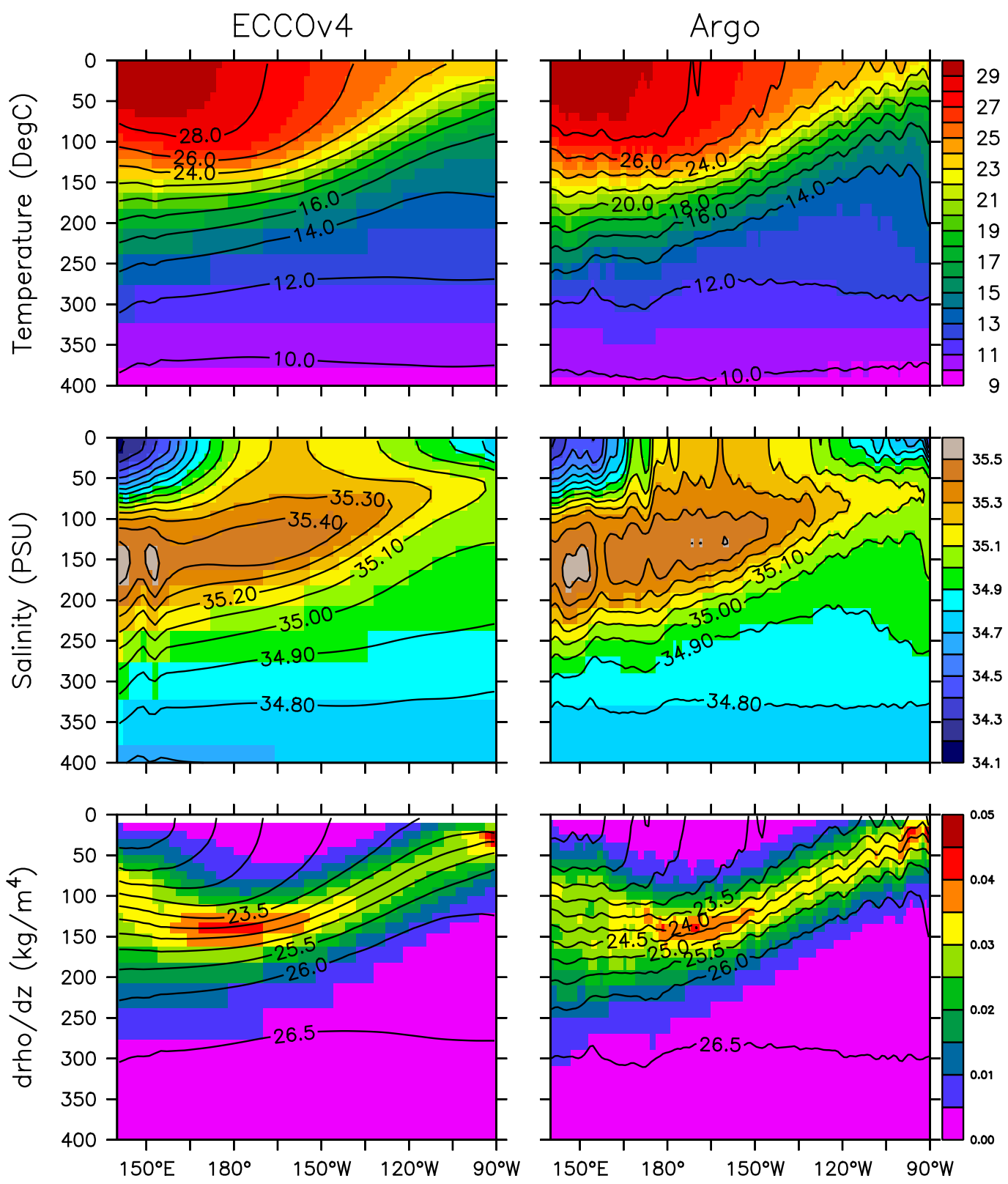

FIG. 2. Mean distribution of (top) temperature, (middle) salinity, and (bottom) pycnocline strength (i.e., vertical density gradient) along the equator from (left) ECCOv4 and (right) Argo. For pycnocline strength, overlaid contours denote potential density. The mean is calculated over 1992-2011 in ECCOv4 and 2004-17 in Argo.

setup is a compromise to be made for the accessibility of the global-scale ocean state estimate problem at this stage (Wunsch and Heimbach 2013).

\section{b. Heat budget in ECCOv4}

The temperature equation implemented in ECCOv4 is the hydrostatic, Boussinesq primitive equation under the $z^{*}$ rescaled vertical coordinate (Adcroft and Campin 2004; Campin et al. 2008; Forget et al. 2015), which reads as

$$
\frac{\partial\left(s^{*} \theta\right)}{\partial t}+\nabla_{z^{*}} \cdot\left(s^{*} \theta \mathbf{v}_{h}\right)+\frac{\partial(\theta w)}{\partial z^{*}}=s^{*}\left(\mathcal{F}_{\theta}+D_{\theta}\right)
$$

where $s^{*}=1+\eta / H, \theta$ is the potential temperature of seawater, $\mathbf{v}_{h}$ is the horizontal velocity vector $\left(\mathbf{v}_{h}=u+v\right)$, and $w$ is the vertical velocity, with $z=\eta$ at the sea surface and $z=-H$ at the sea floor. The $z^{*}$ coordinate is defined as $z^{*}=(z-\eta) / s^{*}$ and $\nabla_{z^{*}}$ is the nabla operator at constant $z^{*}$. The terms $\mathcal{F}_{\theta}$ and $D_{\theta}$ are temperature tendencies due to surface forcing and diffusive processes, 
Mean zonal velocity on the equator
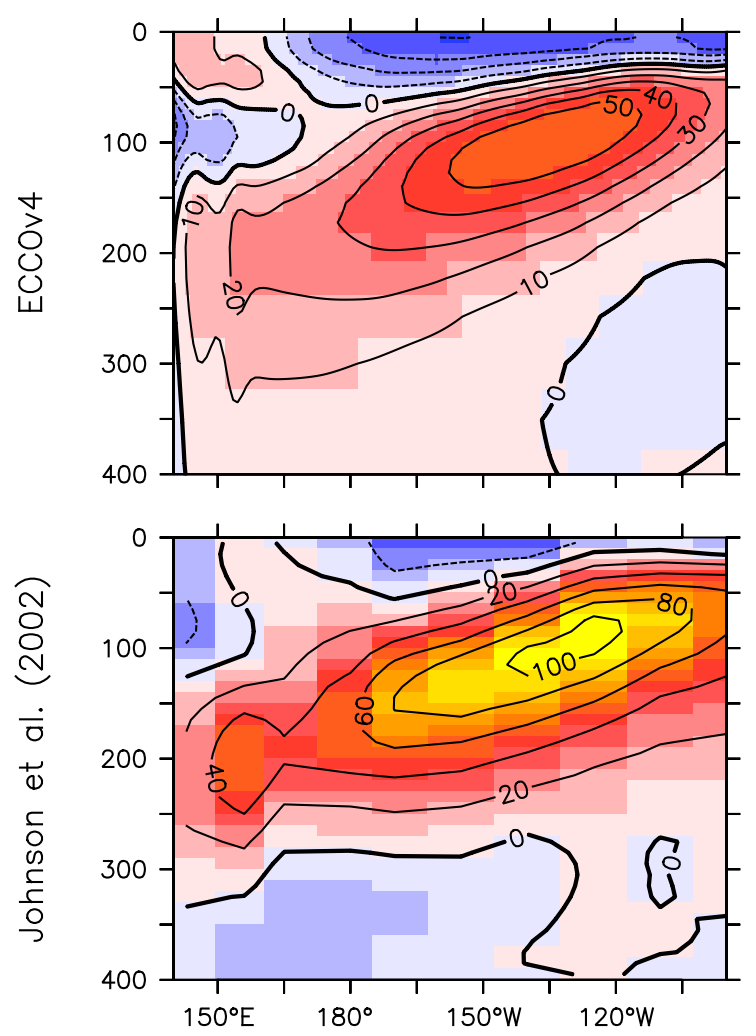

Mean zonal velocity at $140 \mathrm{~W}$
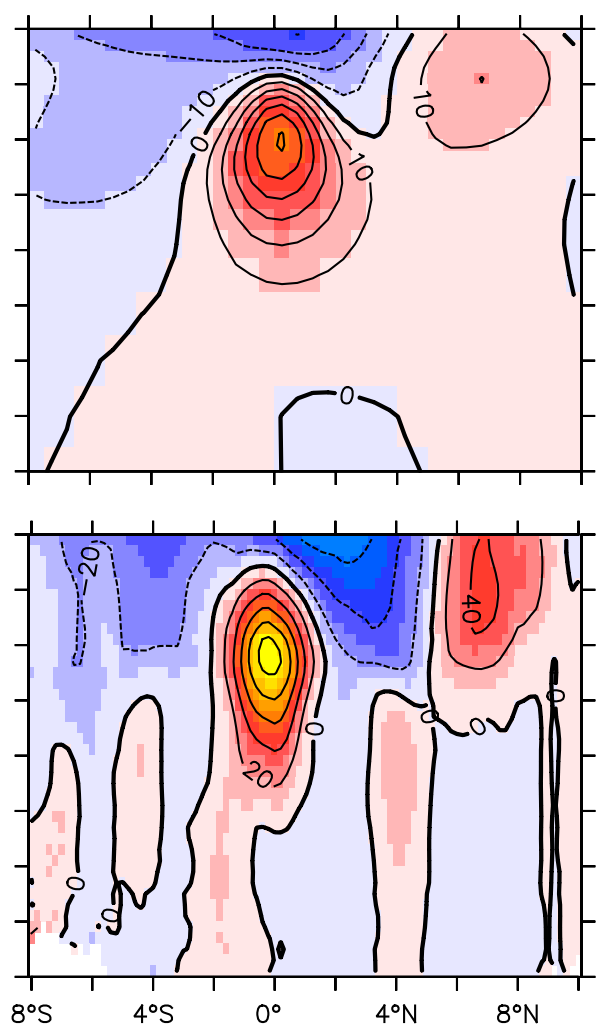

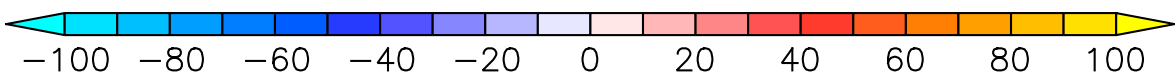

FIG. 3. Mean zonal velocity ( $\mathrm{cm} \mathrm{s}^{-1}$ ) (left) along the equator and (right) across the $140^{\circ} \mathrm{W}$ meridian from (top) the ECCOv4 product and (bottom) Johnson et al. (2002).

respectively. The heat budget analysis is formulated by volume integrating Eq. (1) and applying Gauss's theorem,

$$
\iiint \rho C_{p} \frac{\partial \theta}{\partial t} d V=\iint \rho C_{p}\left(\theta \mathbf{v}+\mathcal{F}_{\theta}+\mathbf{D}_{\theta}\right) \cdot \hat{\mathbf{n}} d A
$$

where $C_{p}$ is the specific heat capacity, $\rho$ is the density of seawater, $\mathbf{v}$ is the three-dimensional velocity vector $(\mathbf{v}=u+v+w), \mathbf{D}_{\theta}$ is the diffusive heat flux vector (standard outputs of ECCOv4), $\mathcal{F}_{\theta}$ is the SHF vector, and $\hat{\mathbf{n}}$ is the inward unit vector normal to the surface of the control volume. From Eq. (1) to Eq. (2), we set $s^{*}$ to 1 as $\eta \ll H$ is a very good approximation in our calculation. In ECCOv4, the temperature is advected by the residual velocity (i.e., v) that comprises two components. One is Eulerian velocity, which is explicitly solved by the momentum equations, while the other is bolus velocity, which is parameterized to represent the effect of mesoscale eddies (Gent and McWilliams 1990).
To study the zonal integrated heat budget, we group terms on the right-hand side (RHS) of Eq. (2) into SHF, convergence of vertical advection and diffusion $(\mathrm{ADVz}+\mathrm{DIFz})$, and convergence of meridional advection (ADVy) (see Figs. 4-7 below). We neglect the diffusion term in the meridional direction, as it is found negligible in our analyses (not shown).

\section{c. Estimation of the ENSO-related component}

The ENSO-related anomalies are estimated via the lagged regression analysis using the N34 index as the independent variable. Lags from -12 to 12 months are examined here to cover the developing (lags $<0$ ), peak $($ lag $=0)$, and decaying phases (lags $>0)$ of ENSO events. All time series have their linear trends and seasonal cycles removed and are further smoothed by a 5-month running mean filter, which is a common practice for ENSO-related studies (e.g., Zhang and McPhaden 2006). The uncertainty of regression and correlation analyses 
is evaluated by the two-sided Student's $t$ test. The effective degree of freedom is calculated as

$$
N_{\text {eff }}=N\left(\frac{1-r_{1} r_{2}}{1+r_{1} r_{2}}\right)
$$

where $N$ is the sample size and $r_{i}$ is the lag- 1 autocorrelation of the time series of interest (Bretherton et al. 1999). The usage of the regression analysis only aims to extract the ENSO-related anomalies consistently over the global ocean following Roemmich and Gilson (2011). We do not assume that ENSO is the dominant signal in the interannual heat budget everywhere globally. The regression analysis can only inform us of the typical behavior of a variable over the evolution of ENSO events. The effects of the nonlinear correlation, the asymmetry between El Niño and La Niña, and different flavors of individual ENSO events (e.g., eastern Pacific vs central Pacific El Niño) cannot be resolved by the regression and therefore are not considered in this study.

\section{d. Ekman and geostrophic transports}

In section $3 \mathrm{c}$, we investigate the mechanisms of meridional volume transport by examining the depthintegrated Ekman transport $\mathbf{V}_{\mathrm{ek}}$ and the geostrophic velocity $\mathbf{v}_{g}$ following

$$
\begin{aligned}
\mathbf{V}_{\mathrm{ek}} & =\frac{1}{\rho f} \boldsymbol{\tau} \times \hat{\mathbf{k}}, \\
\mathbf{v}_{g} & =\frac{1}{\rho f} \hat{\mathbf{k}} \times \nabla p,
\end{aligned}
$$

where $f$ is the Coriolis parameter, $\boldsymbol{\tau}$ is the wind stress, $\hat{\mathbf{k}}$ is the unit vector of the $z$ axis (upward positive), and $p$ is the hydrostatic pressure. The term $p$ is integrated upward using the model velocity at $2000 \mathrm{~m}$ as the boundary condition. This method leads to results that are very similar to setting a no motion layer at $2000 \mathrm{~m}$ in our analysis of interannual variability.

\section{Results}

\section{a. Global integral and regional redistribution}

Full-depth GOHC tendency (GOHCT) from ECCOv4 exhibits strong interannual variability, with a build-up of the GOHC (positive GOHCT) prior to the El Niño peak and a quicker release of the GOHC (negative GOHCT) at and after the peak (Fig. 4a). During the 1997/98 El Niño, the heat build-up rate is about $300 \mathrm{TW}$ (1 TW = $10^{12} \mathrm{~W}$ ) before the event peak, and the heat release rate is about $700 \mathrm{TW}$ after the peak (Fig. 4a). Similar behavior is found for the 2009/10 El Niño. Typical anomalies of the full-depth GOHCT over the course of ENSO events are estimated via the lagged regression over the 20 -yr period (Fig. 4c). The regressed full-depth GOHCT exhibits positive anomalies about $70 \pm 100 \mathrm{TW}^{\circ} \mathrm{C}^{-1}$ before the $\mathrm{El}$ Niño peak, changes sign about 2 months prior to the peak $\left(-60 \pm 100 \mathrm{TW}^{\circ} \mathrm{C}^{-1}\right.$ at zero lag), and reaches a negative maximum of $-120 \pm 95 \mathrm{TW}^{\circ} \mathrm{C}^{-1} 4$ months after the peak. The negative anomaly persists after the 4-month lag, but its magnitude decays with time (Fig. 4c). The 2month lead time of sign change in the full-depth GOHCT relative to the N34 index is not statistically significant.

In ECCOv4, the $\mathrm{N} 34$ index reaches $1.5^{\circ} \mathrm{C}$ during a moderate El Niño event (e.g., 2002/03) and $2.6^{\circ} \mathrm{C}$ during the 1997/98 extreme El Niño event. To put the above regression coefficients into context, the regressed fulldepth GOHCT of $-120 \mathrm{TW}{ }^{\circ} \mathrm{C}^{-1}$ at 4-month lag corresponds to cooling rates of 180 and $312 \mathrm{TW}$ for moderate and extreme El Niño events, respectively. These two numbers are equivalent to 0.5 and $0.9 \mathrm{~W} \mathrm{~m}^{-2} \mathrm{SHF}$ applied to the global ocean, which are of a similar magnitude compared to the global warming signal estimated based on Argo observations by Roemmich et al. (2015).

The regressed full-depth GOHC peaks at lag of -2 months of $2.3 \mathrm{ZJ}{ }^{\circ} \mathrm{C}^{-1}\left(1 \mathrm{ZJ}=10^{21} \mathrm{~J}\right)$, which is comparable to, although smaller than, the $3.4 \mathrm{ZJ}{ }^{\circ} \mathrm{C}^{-1}$ increase found in Johnson and Birnbaum (2017). The discrepancy might result from the following: 1) ECCOv4 simulates weaker ENSO-related GOHC variability than observations and 2) different analysis periods are used [i.e., 2002-16 in Johnson and Birnbaum (2017) vs 19922011 in this study]. In particular, the 2015/16 extreme El Niño event is included in Johnson and Birnbaum (2017) but not in our study with ECCOv4. During ENSO events, the $2.3 \mathrm{ZJ}{ }^{\circ} \mathrm{C}^{-1} \mathrm{GOHC}$ anomaly results in $0.38 \mathrm{~mm}^{\circ} \mathrm{C}^{-1}$ global mean sea level anomaly via thermal expansion, which is weaker than the corresponding impact from ocean mass changes in Cazenave et al. (2014).

The full-depth GOHCT (Fig. 4a) correlates with its 0-440-m counterpart (Fig. 4b, black line) at 0.93 (zero lag, maximum correlation), suggesting that the global integrated heat exchange across $440 \mathrm{~m}$ is negligible on interannual time scales, consistent with Johnson and Birnbaum (2017). The ENSO-related ocean heat content anomalies also exist in $440-2000 \mathrm{~m}$ as evidenced in Fig. 1c during the El Niño peak, but their global integral of $0.1 \mathrm{ZJ}^{\circ} \mathrm{C}^{-1}$ is an order of magnitude smaller than that of $0-100 \mathrm{~m}$ in Fig. $1 \mathrm{a}\left(7.2 \mathrm{ZJ}^{\circ} \mathrm{C}^{-1}\right)$ and 100 $440 \mathrm{~m}$ in Fig. $1 \mathrm{~b}\left(-5.2 \mathrm{ZJ}^{\circ} \mathrm{C}^{-1}\right)$ and thus is negligible for the full-depth GOHC. Changing the $440 \mathrm{~m}$ to adjacent depth layers (i.e., 380 and $510 \mathrm{~m}$ ) in ECCOv4 has little impact on our conclusion. The full-depth GOHCT (Fig. 4a) is more controlled by the tropical SHF (integrated over $30^{\circ} \mathrm{S}-30^{\circ} \mathrm{N}$; Fig. $5 \mathrm{a}$, red line) than the 
a) global full depth

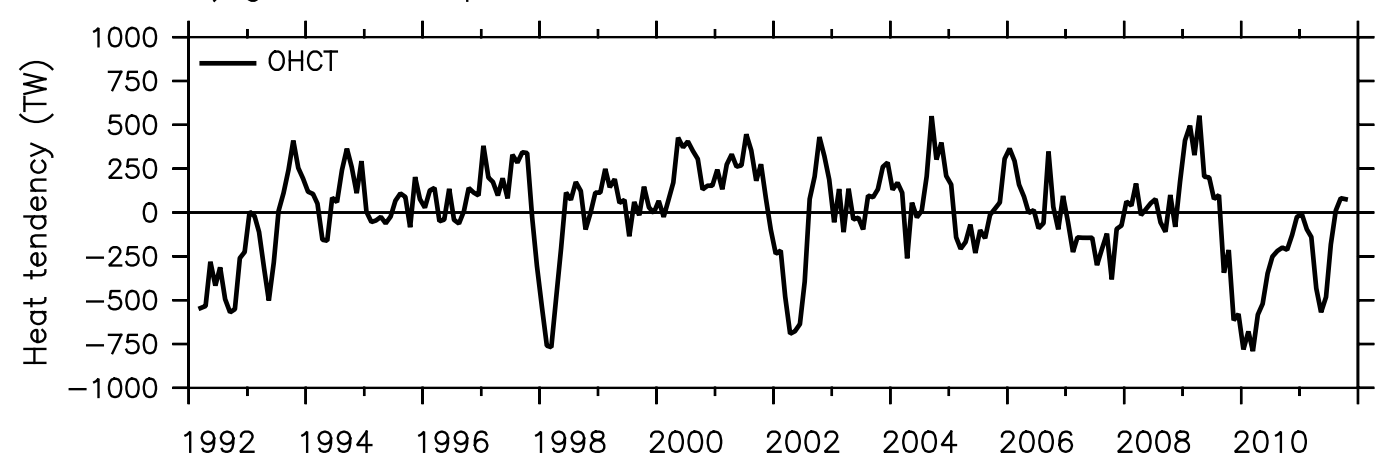

b) global $0-440 \mathrm{~m}$
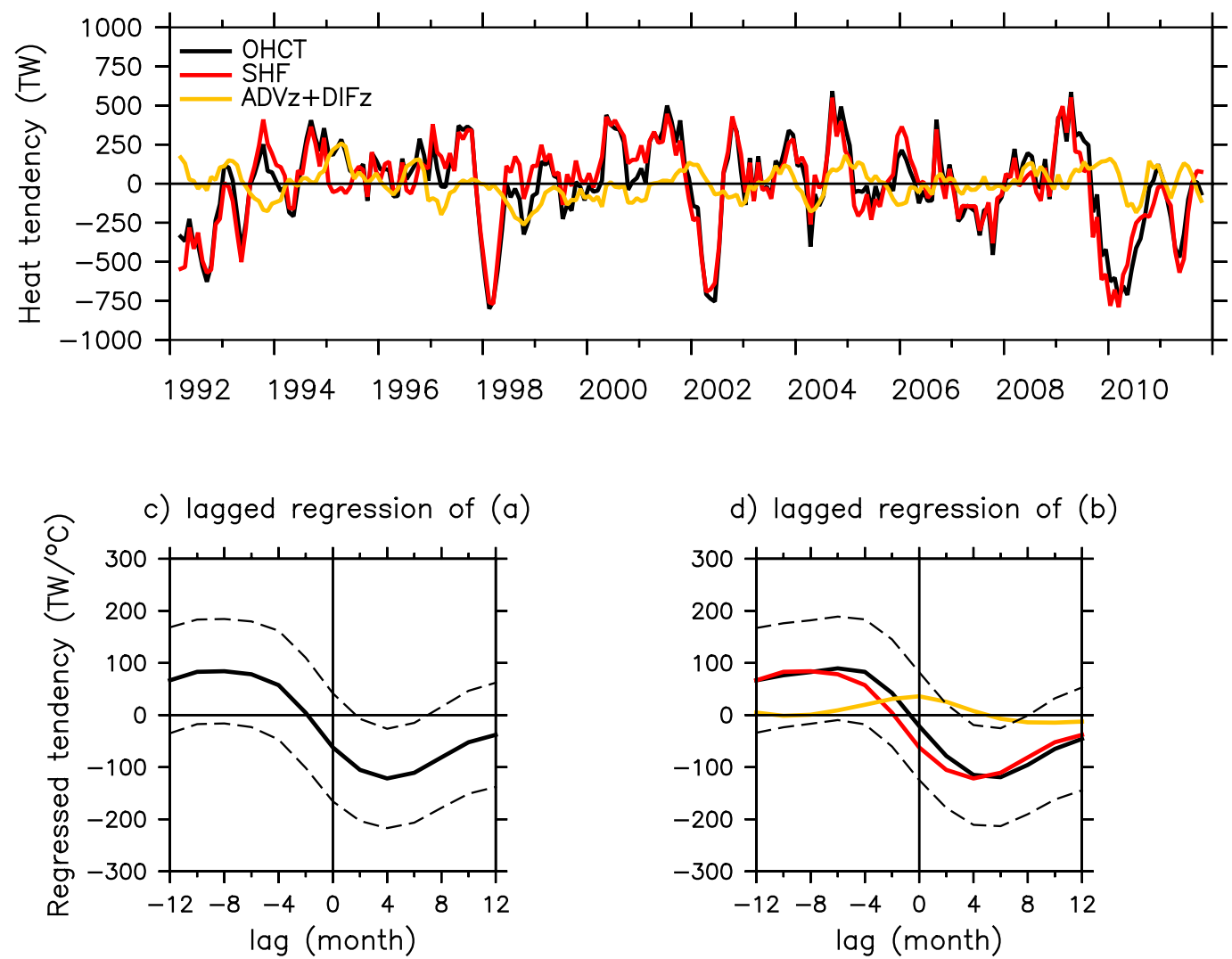

d) lagged regression of (b)

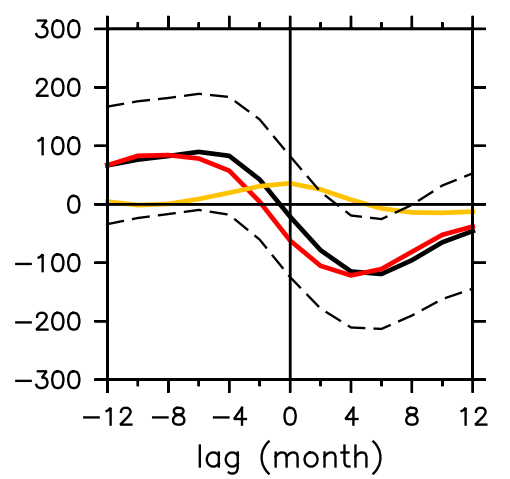

FIG. 4. OHCT integrated globally over the (a) full depth and (b) 0-440-m ocean for 1992-2011. The tendencies due to the SHF and convergence of the vertical advection and diffusion (ADVz+DIFz) are also plotted in (b). (c),(d) Lagged regressions of the time series in (a) and (b) to the N34 index, respectively, with dashed lines denoting the $90 \%$ uncertainty level. The red line of SHF in (b) is equivalent to the full-depth integrated OHCT for the global ocean.

extratropical one (Fig. 5b, red line), as its correlation with the former $(0.78 \pm 0.16$; zero lag $)$ is a factor of 2 stronger than with the latter. The dominance of the tropical SHF in controlling the full-depth GOHCT is also observed in their regressions against the N34 index (cf. Figs. 4c and 5c, red line), except during the decaying phase of El Niño when $20 \%-30 \%$ of the tropical
SHF is offset by that in the extratropics (Fig. 5d, red line). The anomalous heat exchange across $440 \mathrm{~m}$ (Fig. 4b, orange line) is weak compared to the SHF anomaly (Fig. 4b, red line). Its regression has a maximum at zero lag, featuring $30-40 \mathrm{TW}^{\circ} \mathrm{C}^{-1}$ upward heat transport that offsets the cooling tendency from the SHF (cf. Fig. 4d, red and orange lines), resulting in a 
a) tropical $0-440 \mathrm{~m}$

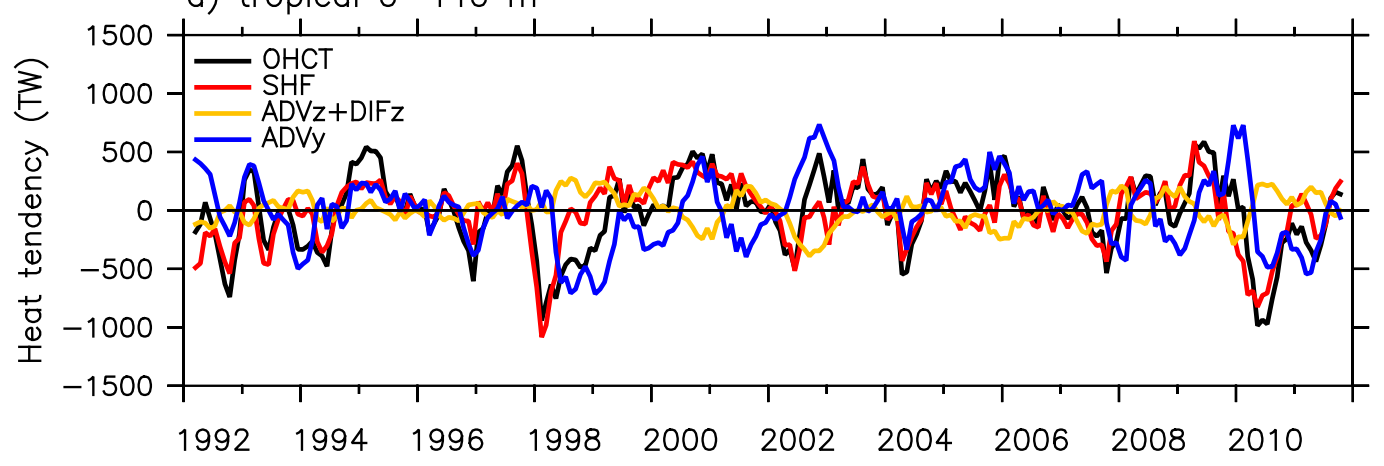

b) extra-tropical $0-440 \mathrm{~m}$
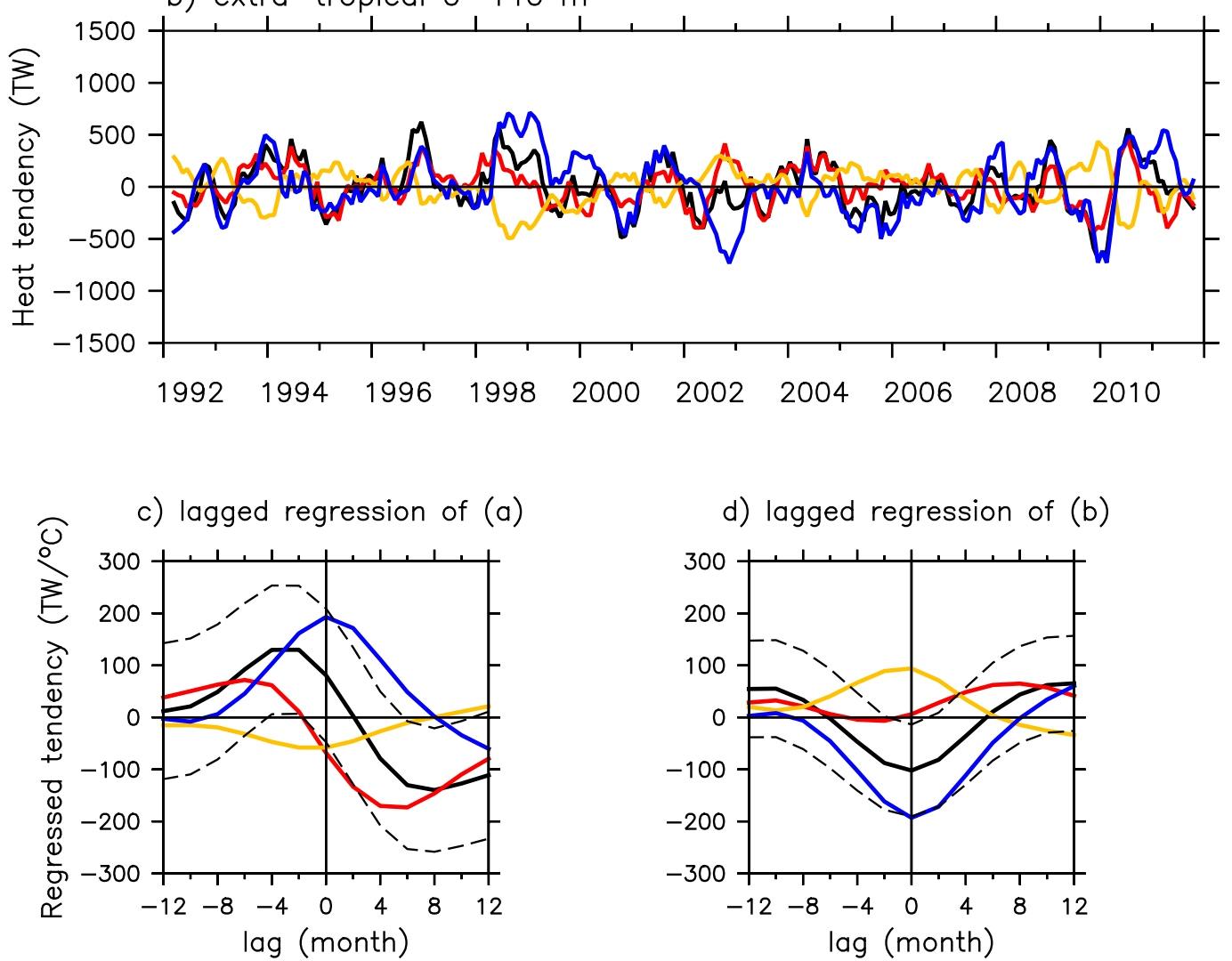

d) lagged regression of (b)

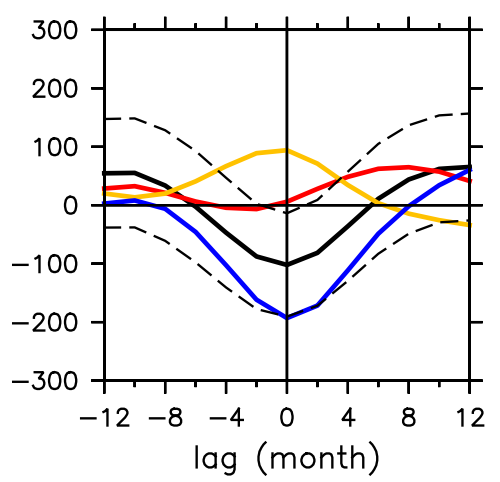

FIG. 5. OHCT integrated over the (a) tropical $\left(30^{\circ} \mathrm{S}-30^{\circ} \mathrm{N}\right)$ and (b) extratropical (outside $\left.30^{\circ} \mathrm{S}-30^{\circ} \mathrm{N}\right)$ regions for the upper $440 \mathrm{~m}$, with the tendencies due to the SHF, ADVz+DIFz, and convergence of meridional advection (ADVy). (c),(d) As in Figs. 4c,d, shown are regressions of (a) and (b) to the N34 index, respectively, with the $90 \%$ uncertainty level indicated by dashed lines.

near-zero tendency of the $0-440-\mathrm{m} \mathrm{GOHC}$ at that time (Fig. 4d, black line).

While the $0-440-\mathrm{m}$ ocean as a whole exhibits anomalous heat exchange with the atmosphere during ENSO events, internal heat redistribution with a rate $2-3$ times greater is observed in both meridional and vertical directions. A huge amount of heat is also redistributed zonally during ENSO events (see section 1), but it does not show up in our zonal integrals. Anomalous convergence/ divergence of the meridional heat transport is visible over the tropical oceans in ECCOv4 (Fig. 5a, blue line). The regressed convergence rate remains positive for lags from -6 to 6 months and reaches a maximum of $190 \pm 110 \mathrm{TW}^{\circ} \mathrm{C}^{-1}$ at zero lag (Fig. 5c, blue line). This suggests that although heat is discharged from the narrow equatorial band during El Niño events as discussed by Meinen and McPhaden 
a) tropical $0-100 \mathrm{~m}$

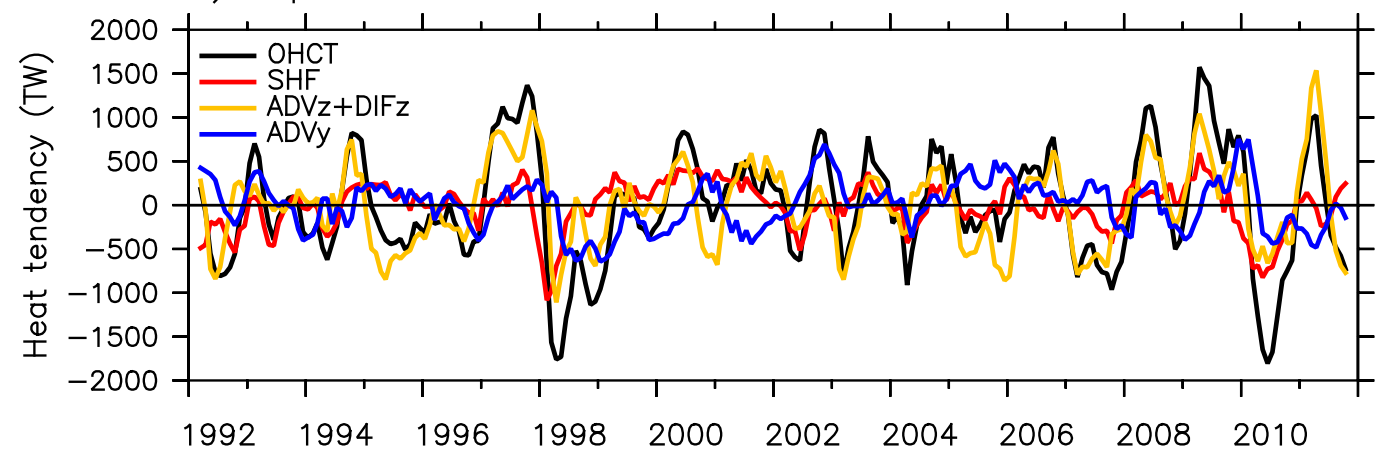

b) extra-tropical $0-100 \mathrm{~m}$
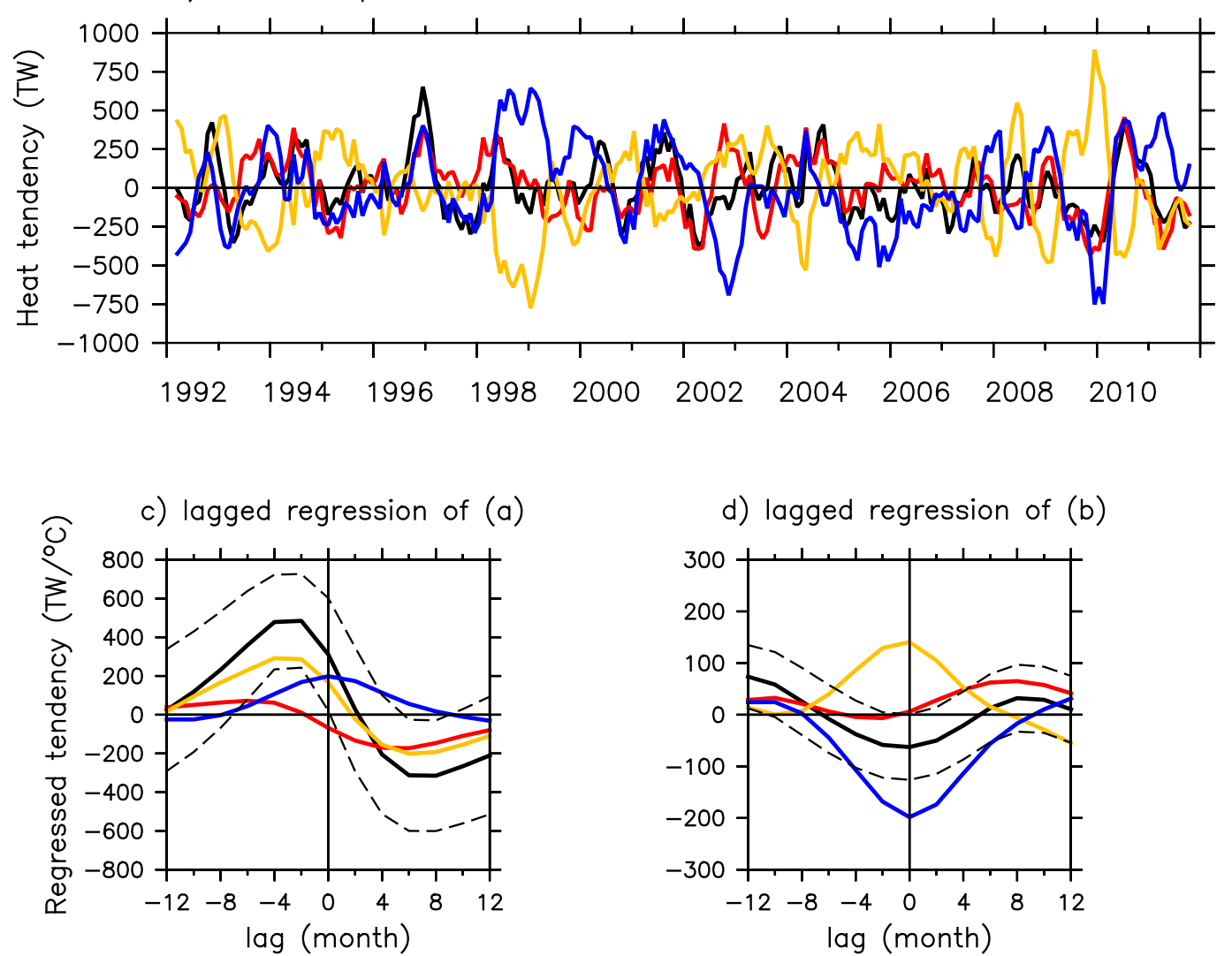

d) lagged regression of (b)

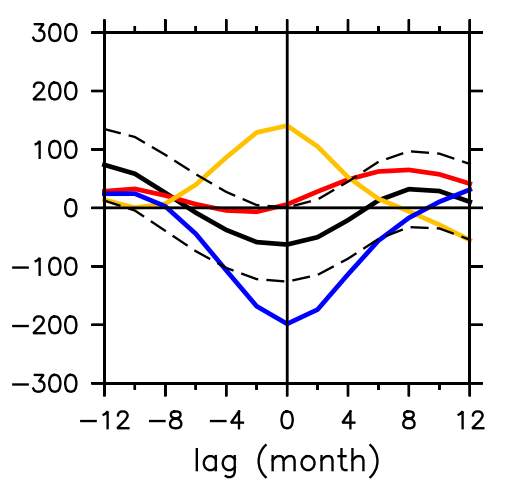

FIG. 6. As in Fig. 5, but for the upper 100-m integral. Note that (b) has a reduced scale on the $y$ axis relative to (a), with a similar reduction for (d) relative to (c).

(2000) and Meinen (2005), the 0-440-m tropical ocean $\left(30^{\circ} \mathrm{S}-30^{\circ} \mathrm{N}\right)$ as a whole gains heat from higher latitudes. The heat convergence rate of $0-440 \mathrm{~m}$ correlates with that of $0-100 \mathrm{~m}$ at 0.98 (zero lag, maximum correlation), indicating that the $0-100-\mathrm{m}$ layer is the main pathway for such heat rearrangement.

Anomalous heat exchange across $440 \mathrm{~m}$ is observed in both tropical and extratropical regions, which offsets about $40 \%$ (at zero lag) of the meridional heat convergence locally (Figs. 5c,d, orange lines). The net vertical heat exchange at that depth, however, is small due to the cancellation between its tropical and extratropical components (Figs. 4b,d, orange lines). In the shallower layer of the tropical oceans, heat is taken into the $0-100-\mathrm{m}$ layer during the developing and peak phases of El Niño, with a rate of $200-300 \mathrm{TW}^{\circ} \mathrm{C}^{-1}$, but is removed from there at a rate of $150-200 \mathrm{TW}^{\circ} \mathrm{C}^{-1}$ during the decaying phase (Fig. 6c, orange line). Previous 

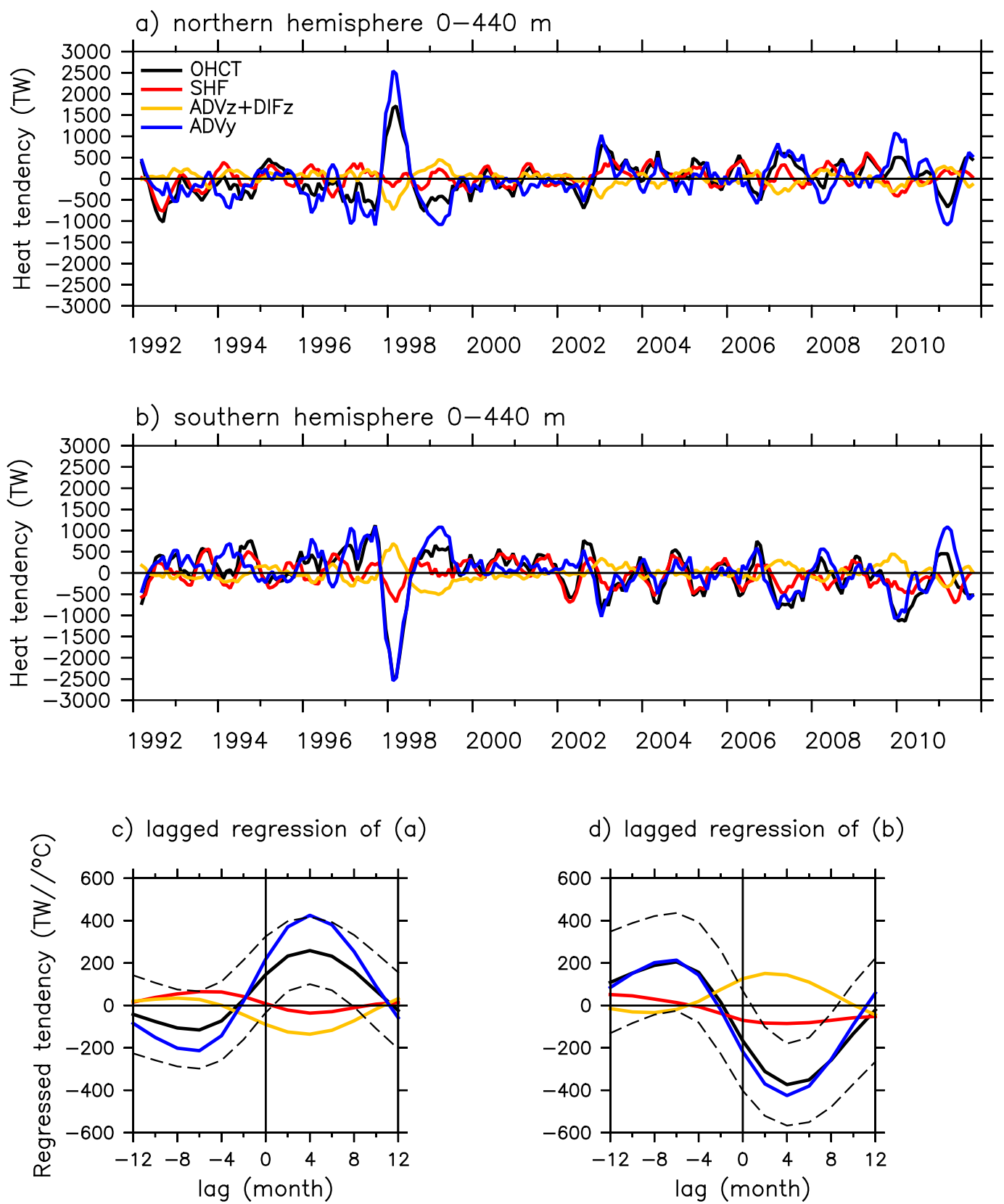

d) lagged regression of (b)

FIG. 7. OHCT integrated in the (a) Northern Hemisphere $\left(0^{\circ}-90^{\circ} \mathrm{N}\right)$ and (b) Southern Hemisphere $7\left(90^{\circ} \mathrm{S}-0^{\circ}\right)$ for the upper $440 \mathrm{~m}$, with the tendencies due to the SHF, ADVz+DIFz, and ADVy. (c),(d) As in Figs. 4c and 4d, shown are regressions of (a) and (b) to the N34 index, respectively, with the $90 \%$ uncertainty level indicated by dashed lines.

studies on the surface-layer heat balance of the Niño-3 region $\left(5^{\circ} \mathrm{S}-5^{\circ} \mathrm{N}, 90^{\circ} \mathrm{E}-150^{\circ} \mathrm{W}\right)$ found an important role of vertical heat advection across $50 \mathrm{~m}$ (e.g., Lee et al. 2004; Zhang and McPhaden 2010). In comparison, the vertical heat transport discussed here is integrated over greater meridional and zonal extents $\left(30^{\circ} \mathrm{S}-30^{\circ} \mathrm{N}, 180^{\circ}-\right.$ $180^{\circ}$ ), thus including not only the classical thermocline and Ekman feedbacks, but also impacts from off-equatorial processes (e.g., Ekman pumping). In the extratropical region, the regressed vertical heat transport across $100 \mathrm{~m}$ has similar behaviors compared to that across $440 \mathrm{~m}$ but with a magnitude 50\% larger (cf. Figs. 5d and 6d, orange lines).

Interhemispheric heat exchange associated with ENSO events is visible in the 0-440-m layer (Figs. 7a,b). The regressed cross-equator heat transport is southward several months prior to the El Niño peak, with a 
maximum of $214 \pm 236 \mathrm{TW}{ }^{\circ} \mathrm{C}^{-1}$ observed at a lag of -6 months (Fig. 7c, blue line). It switches sign at a lag of -3 months and becomes increasingly northward until it reaches a maximum of $425 \pm 182 \mathrm{TW}^{\circ} \mathrm{C}^{-1}$ at 4-month lag (Fig. 7c, blue line). Meinen and McPhaden (2000) have identified a recharge/discharge mode that features a north-south tilting centered at $5^{\circ} \mathrm{N}$ (see their Fig. 3). For this mode, the warm water is accumulated in its southern part (south of $5^{\circ} \mathrm{N}$ ) before El Niño but then discharged into its northern part (north of $5^{\circ} \mathrm{N}$ ) during the event, suggesting a reversal of cross-equator heat transport that is consistent with our estimate. The northward cross-equator heat transport after the peak of $\mathrm{El}$ Niño was also identified in the composite analysis of Zebiak (1989). In addition, we find that the heat gain of the global ocean before the El Niño peak (Fig. 4c) is primarily a result of the SHF in the Northern Hemisphere (Fig. 7c, red line). In contrast, the SHF in the Southern Hemisphere (Fig. 7d, red line) is more important in removing heat from the global ocean during the peak and decaying phases of El Niño.

\section{b. A two-dimensional diagram}

The meridional and vertical heat transports discussed above (Figs. 4-7) reveal how heat is redistributed across latitudes and depths in the global ocean during ENSO events (Fig. 8). During the onset of El Niño (using lag $=-4$ months as an example), heat is injected into the $0-100-\mathrm{m}$ layer of the tropical oceans via the vertical and meridional heat transports and the SHF (Fig. 8a). The heat injection persists to around the event peak (zero lag) with a more vigorous heat transport from the northern extratropical oceans, but a cooling tendency from the SHF in the tropics (Fig. 8b). During the decaying phase of El Niño (taking lag = 4 months as an example), the extratropical oceans continue to transport heat into the $0-100-m$ layer of the tropical oceans, while a similar amount of heat is moved to below $100 \mathrm{~m}$ from there (Fig. 8c). At the same time, the SHF removes heat from the ocean at a rate of $170 \mathrm{TW}{ }^{\circ} \mathrm{C}^{-1}$ in the tropics while it only warms the higher latitudes by $45 \mathrm{TW}^{\circ} \mathrm{C}^{-1}$, thus resulting in a net heat loss of the global ocean. In the above processes, most of the ocean heat transport is due to the advection process. The diffusion process is only nonnegligible for that across $100-\mathrm{m}$ depth where it tends to counteract the advection before and at the peak of El Niño. The 4-month lag is selected to capture the negative maximum in the regressed full-depth GOHCT (Fig. 4c). The interhemispheric heat exchange described in Fig. 7 is similarly summarized in Figs. 8d and 8e, with a focus on developing and decaying phases, due to its weak in-phase regressions.
It has been envisioned by Roemmich and Gilson (2011) that the ENSO-related vertical heat redistribution might alter air-sea interaction and facilitate a net heat loss of the global ocean via the SHF during El Niño events, while the opposite-a net heat gain-is the case for La Niña events. In the tropics, the correlation between the 0-100-m ocean heat content and the SHF (both are spatially integrated) peaks at $-0.56 \pm 0.30$ when the latter lags the former by 4 months in ECCOv4. The negative correlation suggests that the SHF tends to damp the heat content variations in the upper tropical oceans. Similar findings were identified for the narrower equatorial band previously (e.g., Sun and Trenberth 1998; Wang and McPhaden 2000; Zhang and McPhaden 2010), while our tropical integrated results emphasize the delay nature of such negative feedback. The analysis is repeated for the extratropical oceans, but no significant correlation between the SHF and heat content is identified. An important insight we can draw from these results is that the oceanic heat redistribution is central in affecting the full-depth GOHC during ENSO events, even though via an indirect manner. Specifically, as heat is redistributed into or out of the upper tropical oceans, where the oceans can effectively affect the atmosphere, it modulates the SHF anomalies, which ultimately determines the changes of the full-depth GOHC. Despite our focus on the meridional and vertical components, it must be noted that the zonal process also contributes to anomalous heat transports depicted in Fig. 8, for instance via its impact on the west-east tilting of the thermocline, as suggested by previous studies (e.g., Zebiak 1989; Brady 1994; Meinen and McPhaden 2001).

\section{c. Mechanisms of heat advection}

To investigate what drives the ENSO-related heat redistribution across latitudes and depths, we decompose the heat advection term $\mathbf{v} \theta$ into $\mathbf{v}^{\prime} \bar{\theta}, \overline{\mathbf{v}} \theta^{\prime}, \mathbf{v}^{\prime} \theta^{\prime}$, and $\overline{\mathbf{v}} \bar{\theta}$, where $\mathbf{v}=u+v+w$, overbars denote the seasonal climatology, and primes denote anomalies relative to that. The first three terms are interpreted as anomalous advection of mean temperature $\mathbf{v}^{\prime} \bar{\theta}$, mean advection of anomalous temperature $\overline{\mathbf{v}} \theta^{\prime}$, and nonlinear advection $\mathbf{v}^{\prime} \theta^{\prime}$, respectively. The last term, $\overline{\mathbf{v}} \bar{\theta}$, does not contain any variability on interannual time scales and thus is ignored in the following analyses. The anomalous advection of mean temperature $\mathbf{v}^{\prime} \bar{\theta}$ is the dominant process in determining the heat advection anomalies in Figs. 5-7, except in the tropical oceans where $w^{\prime} \bar{\theta}, \bar{w} \theta^{\prime}$, and $w^{\prime} \theta^{\prime}$ all contribute to the heat exchange across $100 \mathrm{~m}$ (Fig. 9). For instance, the term $\bar{w} \theta^{\prime}$ accounts for about $200 \mathrm{TW}^{\circ} \mathrm{C}^{-1}$ upward heat transport at zero lag (Fig. 9c, orange line), which is comparable to $w^{\prime} \bar{\theta}$ (Fig. 9c, red line). The term $w^{\prime} \theta^{\prime}$, in contrast, provides about $90 \mathrm{TW}^{\circ} \mathrm{C}^{-1}$ downward heat transport at 


\section{Heat exchange across the tropical and extra-tropical regions in ECCOv4}

a) Developing phase lag $=-4$ months

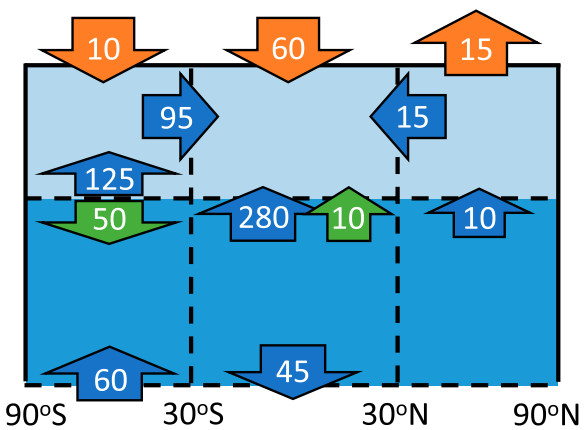

b) Peak phase lag $=0$ month

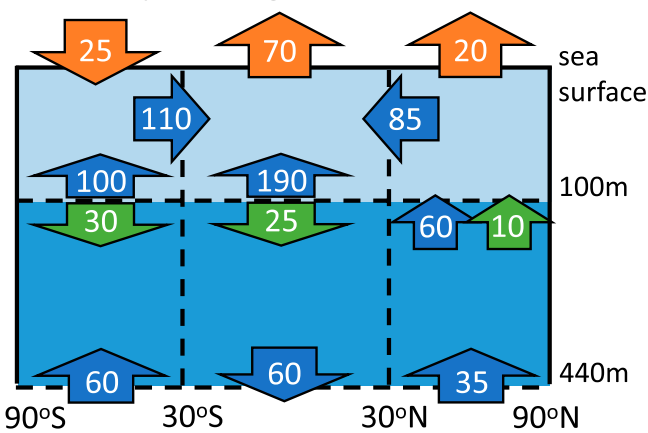

c) Decaying phase lag $=4$ months
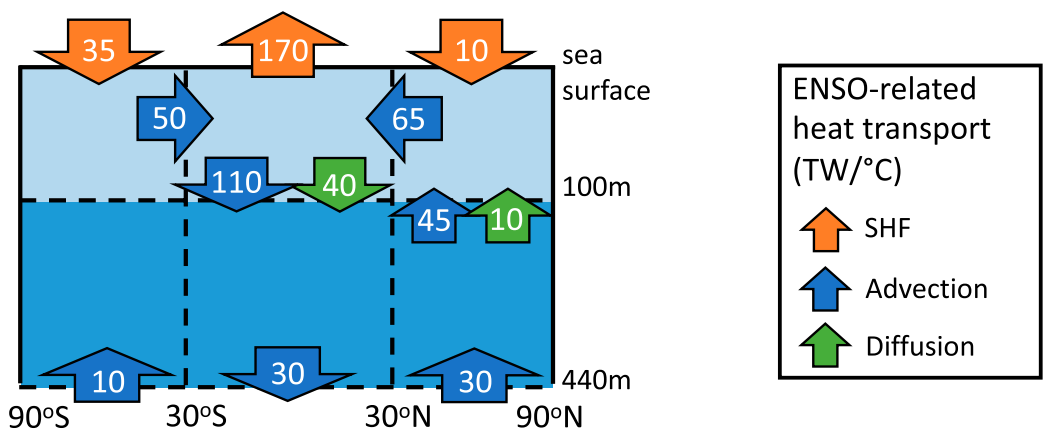

Heat exchange across the hemispheres in ECCOv4

d) Developing phase lag $=-4$ months

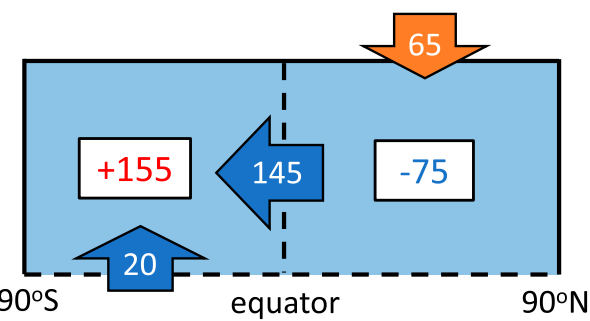

e) Decaying phase lag $=4$ months

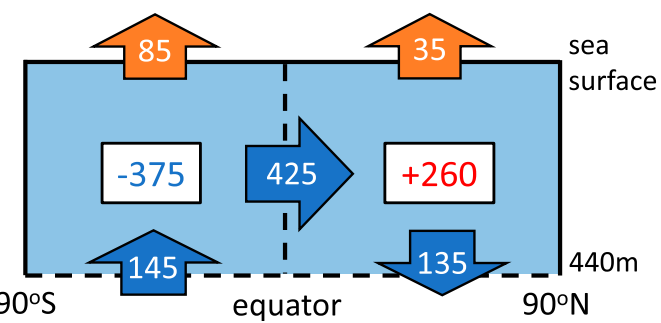

FIG. 8. Schematic of anomalous heat transports associated with ENSO in the upper $440 \mathrm{~m}$ shown as a function of latitude and depth. (a)-(c) Anomalous heat exchange across the $30^{\circ} \mathrm{S}$ and $30^{\circ} \mathrm{N}$ parallels, and the $100-$ and $440-\mathrm{m}$ depths at different phases of El Niño events. (d),(e) Here focus is on the interhemispheric heat exchanges (arrows) and tendencies in the hemispheric heat content (boxes). Results are based on Figs. 4-7, but the heat transport is further separated into the advection and diffusion terms, and the integral of the extratropical region is decomposed into that of its northern and southern parts. The arrows and signs are shown for El Niño events, but they would be reversed for La Niña events. Values less than $10 \mathrm{TW}^{\circ} \mathrm{C}^{-1}$ are neglected.

zero lag (Fig. 9c, blue line), partially offsetting the upward transport by the other two terms. The $\bar{w} \theta^{\prime}, w^{\prime} \bar{\theta}$, and $w^{\prime} \theta^{\prime}$ components were previously used to understand the surfacelayer heat balance of the equatorial Pacific, with the former two being referred to as the thermocline and Ekman feedbacks, respectively, and important roles being identified for all three of them (Jin et al. 2006; Zhang and McPhaden 2010).
The section-integrated $\mathbf{v}^{\prime} \bar{\theta}$ can be decomposed into two components following the method of Macdonald and Baringer (2013):

$$
\iint \mathbf{v}^{\prime} \bar{\theta} \cdot \hat{\mathbf{n}} d A=\overbrace{[\bar{\theta}] \iint \mathbf{v}^{\prime} \cdot \hat{\mathbf{n}} d A}^{\text {non-mass-balanced }}+\overbrace{\iint\left\langle\mathbf{v}^{\prime}\right\rangle\langle\bar{\theta}\rangle \cdot \hat{\mathbf{n}} d A}^{\text {mass-balanced }},
$$


a) meridional convergence $30 \mathrm{~S}-30 \mathrm{~N}$ 0-100m in Fig.6c

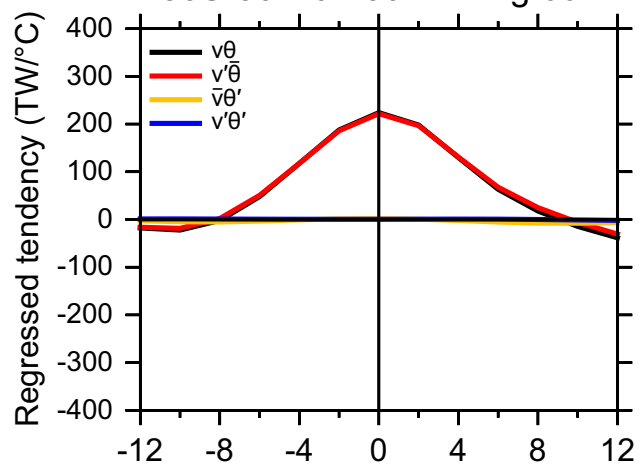

c) vertical advection $100 \mathrm{~m}$ $30 \mathrm{~S}-30 \mathrm{~N}$ in Fig.6c

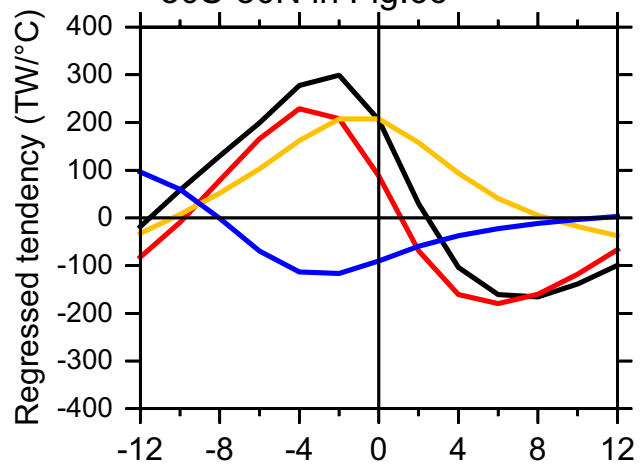

e) vertical advection $100 \mathrm{~m}$ outside 30S-30N in Fig.6d

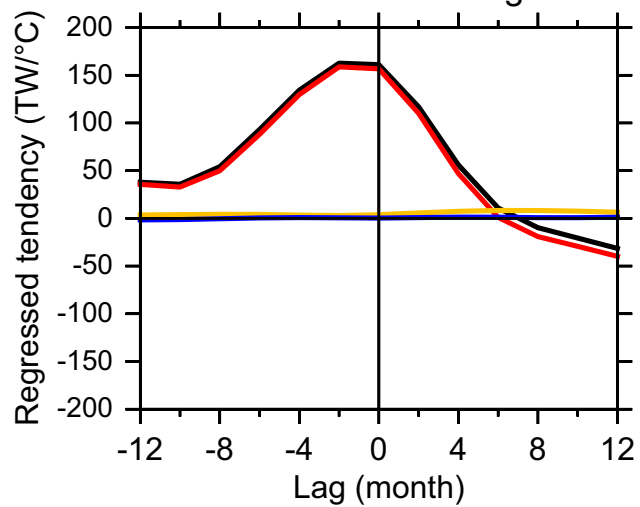

b) cross-equator 0-440m in Fig.7c

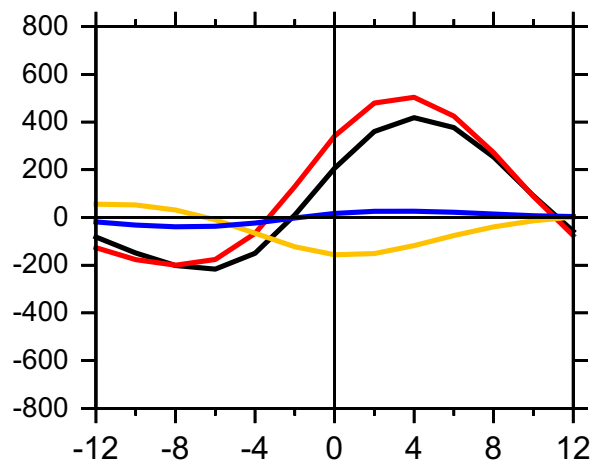

d) vertical advection $440 \mathrm{~m}$ $30 \mathrm{~S}-30 \mathrm{~N}$ in Fig.5c

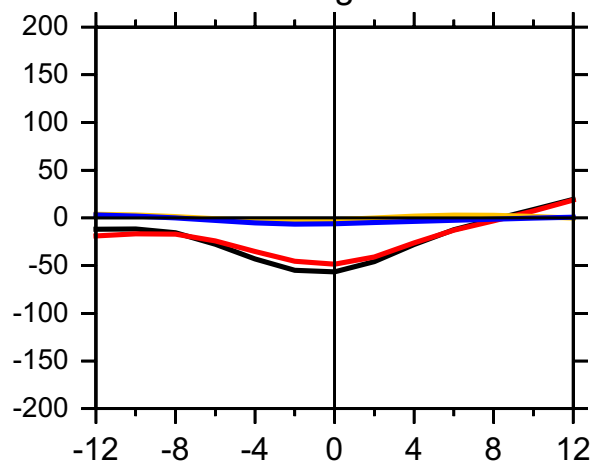

f) vertical advection $440 \mathrm{~m}$ outside $30 \mathrm{~S}-30 \mathrm{~N}$ in Fig.5d

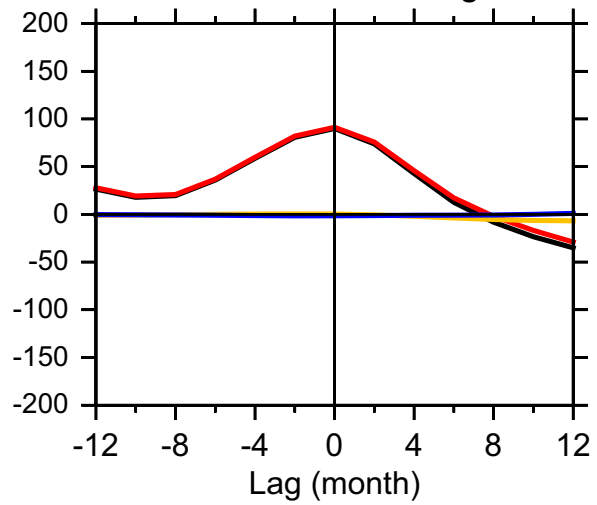

FIG. 9. (a)-(f) Decomposing the lagged regression of heat advection $\mathbf{v} \theta$ (black) in Figs. 5-7 into contributions from 1) anomalous advection of mean temperature $\mathbf{v}^{\prime} \bar{\theta}$ (red), 2) mean advection of anomalous temperature $\overline{\mathbf{v}} \theta^{\prime}$ (orange), and 3) nonlinear advection $\mathbf{v}^{\prime} \theta^{\prime}$ (blue). Overbars denote the seasonal climatology, and primes denote anomalies relative to that. Positive values correspond to northward transports in (b) and upward transports in (c)-(f).

where the square brackets denote the spatial mean, and the angle brackets denote spatial deviations relative to that (e.g., $\mathbf{v}^{\prime}=\left[\mathbf{v}^{\prime}\right]+\left\langle\mathbf{v}^{\prime}\right\rangle$ at each time step). The first term on the RHS of Eq. (6) comes with a sectionintegrated mass transport and is referred to as the nonmass-balanced component. In contrast, the second term on the RHS of Eq. (6) is independent of the sectionintegrated mass transport and thus is called the massbalanced component (Macdonald and Baringer 2013). It is useful to distinguish these two terms because the sections used to integrate the heat advection in this study do not guarantee zero mass transport [also see 
Gregory (2000)]. The mass-balanced meridional heat transport can be further split into the horizontal (gyre) and vertical (baroclinic) components as follows:

$$
\begin{aligned}
\iint\left\langle\boldsymbol{v}^{\prime}\right\rangle\langle\bar{\theta}\rangle d x d z= & \overbrace{\iint\left\langle\boldsymbol{v}^{\prime}\right\rangle(z)\langle\bar{\theta}\rangle(z) d x d z}^{\text {baroclinic }} \\
& +\overbrace{\iint\left\langle\boldsymbol{v}^{\prime}\right\rangle(x, z)\langle\bar{\theta}\rangle(x, z) d x d z}^{\text {gyre }},
\end{aligned}
$$

where $\left\langle\boldsymbol{v}^{\prime}\right\rangle(z)$ is the zonal average of $\left\langle\boldsymbol{v}^{\prime}\right\rangle$ at a given latitude, and $\left\langle\boldsymbol{v}^{\prime}\right\rangle(x, z)=\left\langle\boldsymbol{v}^{\prime}\right\rangle-\left\langle\boldsymbol{v}^{\prime}\right\rangle(z)$. The terms $\langle\bar{\theta}\rangle(z)$ and $\langle\bar{\theta}\rangle(x, z)$ are defined in the same manner. Similarly, the mass-balanced vertical heat transport can be split into the meridional and zonal cell components as follows:

$$
\begin{aligned}
\iint\left\langle w^{\prime}\right\rangle\langle\bar{\theta}\rangle d x d y \approx & \overbrace{\iint\left\langle w^{\prime}\right\rangle(y)\langle\bar{\theta}\rangle(y) d x d y}^{\text {meridional cell }} \\
& +\overbrace{\iint\left\langle w^{\prime}\right\rangle(x, y)\langle\bar{\theta}\rangle(x, y) d x d y}^{\text {zonal cell }},
\end{aligned}
$$

where $\left\langle w^{\prime}\right\rangle(y)$ is the zonal average of $\left\langle w^{\prime}\right\rangle$ at a given depth, and $\left\langle w^{\prime}\right\rangle(x, y)=\left\langle w^{\prime}\right\rangle-\left\langle w^{\prime}\right\rangle(y)$. The same notation applies to $\langle\bar{\theta}\rangle(y)$ and $\langle\bar{\theta}\rangle(x, y)$.

The regression of $v^{\prime} \bar{\theta}$ comprises significant amounts of the non-mass-balanced heat transport (cf. Fig. 10, black and red lines). During El Niño, the non-mass-balanced component features upward heat transports outside the tropics (Figs. 10e,f, red lines), equatorward transports across $30^{\circ} \mathrm{S}$ and $30^{\circ} \mathrm{N}$ sections at $0-100 \mathrm{~m}$ (Fig. 10a, red line), and downward transports in the tropics (Figs. 10c,d, red lines). These non-mass-balanced heat transports are driven by volume transports integrated over corresponding sections [Eq. (6)] that feature a meridional overturning circulation (Fig. 11). Over the course of El Niño (Figs. 11a-c), seawater upwells in the extratropical region and then converges toward the tropics, where it is fed into a downwelling branch. The fact that the behavior of the regressed non-mass-balanced heat transports is temporally coherent (peak at similar lags; Fig. 10, red line) is likely due to the constraint of the continuity equation. That is to say, any meridional convergence of volume transport in the upper tropics must be balanced by downwelling and upwelling in the tropical and extratropical regions, respectively, so as to satisfy the continuity requirement. In the upper tropical oceans $(0-100 \mathrm{~m})$, the meridional convergence of volume transport is dominated by its Ekman component [Eq. (4)], as the two correlate at $0.96 \pm 0.08$ (zero lag). In contrast, the correlation with its geostrophic component [Eq. (5)] is low at $0.37 \pm 0.37$ (zero lag). The relative importance between the Ekman and geostrophic components identified here is different from that identified in lower latitudes (e.g., $\left.5^{\circ} \mathrm{S}-5^{\circ} \mathrm{N}\right)$ where the geostrophic component is also important in affecting the meridional volume convergence (Meinen and McPhaden 2001).

The mass-balanced component is comparable to the non-mass-balanced component in the regression of $w^{\prime} \bar{\theta}$ (Figs. 10c-f, blue and orange lines). In the tropical region, the mass-balanced vertical heat transport mostly results from the zonal cell component, while at higher latitudes it is due to the meridional cell component [Eq. (8)]. To gain insight as to how these mass-balanced heat transports are generated, we examine the spatial structures of the ENSO-related overturning circulations. The streamfunctions for meridional $\psi_{\mathrm{MOC}}$ and zonal $\psi_{\mathrm{ZOC}}$ overturning circulations are defined as follows:

$$
\begin{aligned}
& \psi_{\mathrm{MOC}}=\int_{90^{\circ} \mathrm{S}}^{y} \int_{180^{\circ} \mathrm{W}}^{180^{\circ} \mathrm{E}} w-w_{\mathrm{nmb}} d x d y, \\
& w_{\mathrm{nmb}}=\left\{\begin{array}{cc}
{[w](x, z)_{90^{\circ} \mathrm{S}-30^{\circ} \mathrm{S}},} & 90^{\circ} \mathrm{S}<y<30^{\circ} \mathrm{S}, \\
{[w](x, z)_{30^{\circ} \mathrm{S}-30^{\circ} \mathrm{N}},} & 30^{\circ} \mathrm{S}<y<30^{\circ} \mathrm{N}, \\
{[w](x, z)_{30^{\circ} \mathrm{N}-90^{\circ} \mathrm{N}},} & 30^{\circ} \mathrm{N}<y<90^{\circ} \mathrm{N},
\end{array}\right. \\
& \psi_{\mathrm{ZOC}}=\int_{20^{\circ} \mathrm{E}}^{x} \int_{30^{\circ} \mathrm{S}}^{30^{\circ} \mathrm{N}} w-w_{\mathrm{nmb}} d y d x, \\
& w_{\mathrm{nmb}}=[w](y, z)_{20^{\circ} \mathrm{E}-20^{\circ} \mathrm{W}} .
\end{aligned}
$$

As we aim to explain the mass-balanced vertical heat transport, the non-mass-balanced vertical velocity $w_{\mathrm{nmb}}$ is removed in Eqs. (9) and (10). Specifically, $[w](x, z)_{y_{1}-y_{2}}$ is the meridional average of vertical velocity over the latitudinal band $y_{1}-y_{2}$. The term $[w](y, z)_{x_{1}-x_{2}}$ is similar to $[w](x, z)_{y_{1}-y_{2}}$ but for the zonal average. Since the vertical heat transport is integrated for the tropical and extratropical regions separately in this study, $w_{\mathrm{nmb}}$ is calculated for different latitudinal bands separately as well in Eq. (9). Nonetheless, the structure of the overturning cell revealed by the streamfunction is not sensitive to the removal of $w_{\mathrm{nmb}}$ based on our tests. The term $\psi_{\mathrm{ZOC}}$ is only integrated for the tropical band because the zonal cell component is negligible outside there (Figs. 10e,f, blue lines). The tropical integral makes $\psi_{\text {ZOC }}$ a "pseudo" streamfunction as the divergence of meridional velocity is not zero when integrated for $30^{\circ} \mathrm{S}-30^{\circ} \mathrm{N}$ only. However, the circulation pattern revealed by vertical and zonal velocities (not shown) agrees well with that revealed by $\psi_{\mathrm{ZOC}}$ in the tropical band, justifying the use of $\psi_{\mathrm{zOC}}$ here.

In the extratropical region, the regression of $\psi_{\mathrm{MOC}}$ [Eq. (9)] reveals an anticlockwise cell at $90^{\circ}-30^{\circ} \mathrm{S}$ and a clockwise cell at $30^{\circ}-90^{\circ} \mathrm{N}$ (Fig. 12). The clockwise cell is weaker than $0.5 \mathrm{~Sv}^{\circ} \mathrm{C}^{-1}\left(1 \mathrm{~Sv}=10^{6} \mathrm{~m}^{3}\right)$ at a lag of -4 months (Fig. 12a) and grows to about $1 \mathrm{~Sv}^{\circ} \mathrm{C}^{-1}$ at 
a) meridional convergence

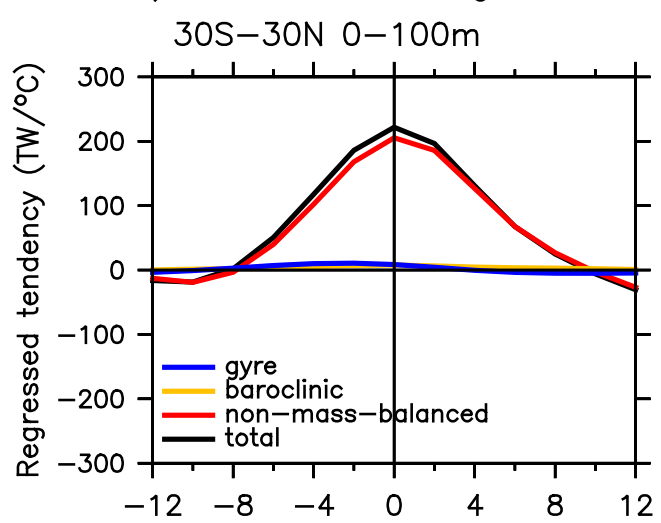

c) vertical advection $30 \mathrm{~S}-30 \mathrm{~N} 100 \mathrm{~m}$

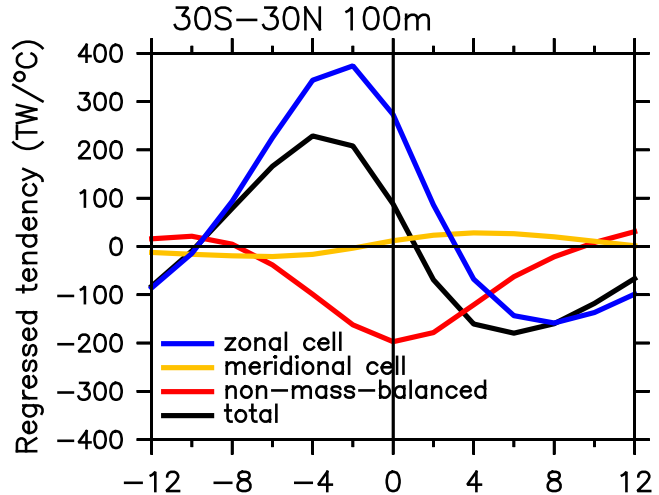

e) vertical advection outside $30 \mathrm{~S}-30 \mathrm{~N} 100 \mathrm{~m}$

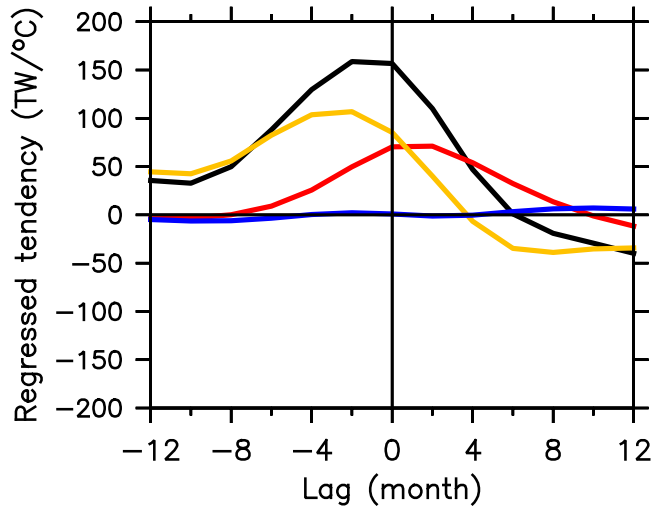

b) cross-equator $0-440 \mathrm{~m}$

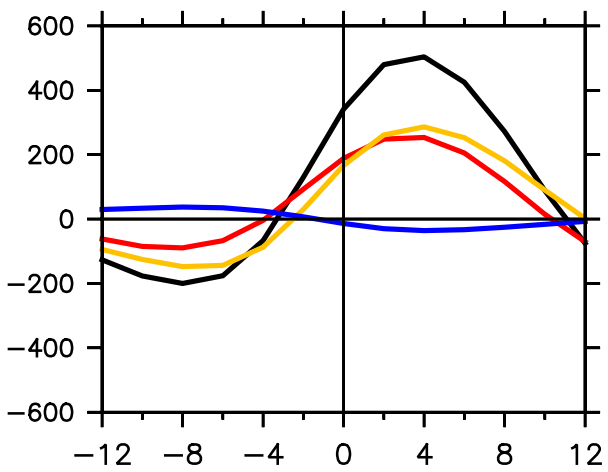

d) vertical advection 30S-30N 440m

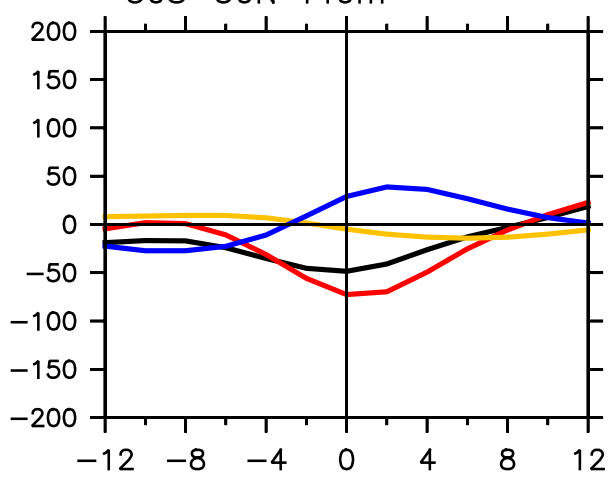

f) vertical advection outside $30 \mathrm{~S}-30 \mathrm{~N} 440 \mathrm{~m}$

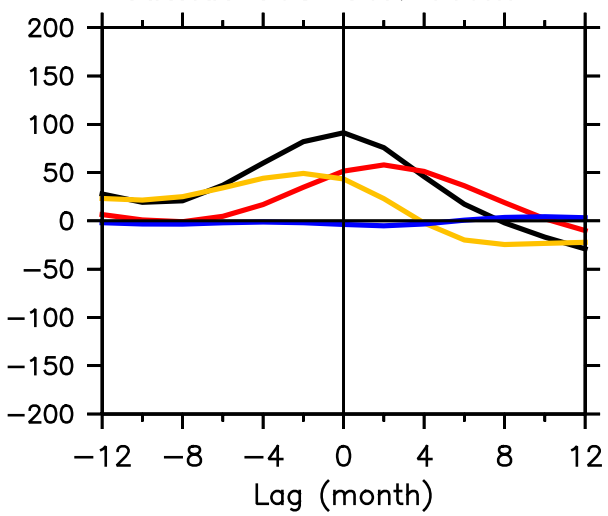

FIG. 10. (a)-(f) Decomposition of $\mathbf{v}^{\prime} \bar{\theta}$ (black) in Figs. 5-7 into the non-mass-balanced (red) and mass-balanced components. For meridional advections in (a) and (b), the mass-balanced component is split into the gyre (blue) and baroclinic (orange) components, while in (c)-(f) the mass-balanced component in vertical advections is split into the zonal (blue) and meridional (orange) cell components.

0 - and 4-month lags (Figs. 12b,c). The anticlockwise cell in $90^{\circ}-30^{\circ} \mathrm{S}$, on the other hand, has a magnitude of $2 \mathrm{~Sv}^{\circ} \mathrm{C}^{-1}$ at lags of -4 and 0 months (Figs. 12a,b) but decays into a two-cell structure at a 4-month lag (Fig. 12c). The anticlockwise cell at $90^{\circ}-30^{\circ} \mathrm{S}$ and the clockwise cell at $30^{\circ}-90^{\circ} \mathrm{N}$ bring the warm subtropical water upward but move the cold polar water downward around the El Niño peak, which explains the upward heat transport found in the meridional cell component at that time [Eq. (8); Figs. 10e,f, orange lines]. 


\section{ENSO-related volume transport $\left(\mathrm{Sv} /{ }^{\circ} \mathrm{C}\right)$}

a) Developing phase lag $=-4$ months

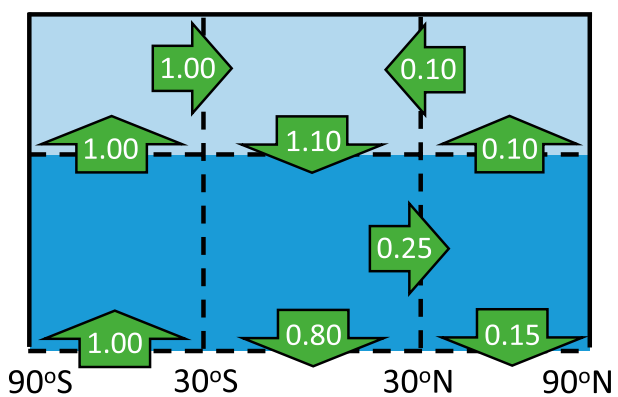

b) Peak phase lag $=0$ month

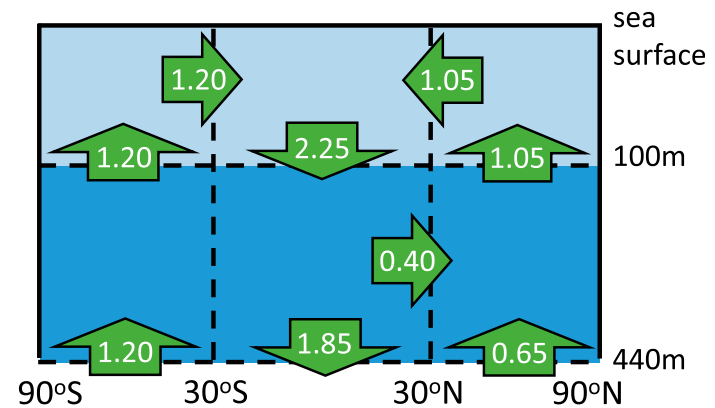

c) Decaying phase lag $=4$ months

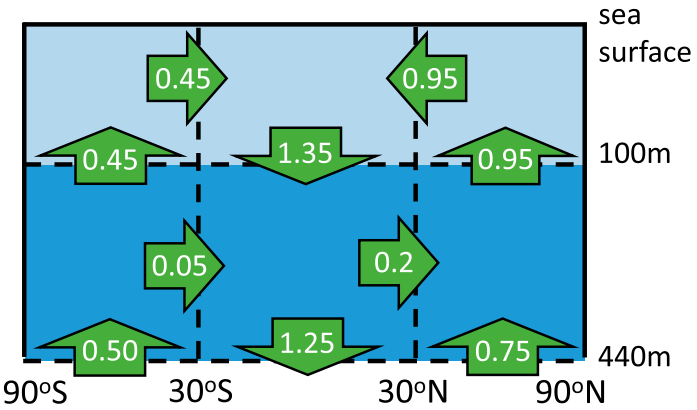

FIG. 11. Schematic of anomalous volume transports $\left(\mathrm{Sv}^{\circ} \mathrm{C}^{-1}\right)$ associated with ENSO in the upper $440 \mathrm{~m}$ shown as a function of latitude and depth. The regressed anomalous transports at lags of (a) -4 , (b) 0 , and (c) 4 months are labeled. The arrows are shown for El Niño events and would be reversed for La Niña events.

In the tropical region, the meridional cell has a much weaker impact on the vertical heat transport than it has in the extratropical region (cf. Figs. 10c,d and Figs. 10e,f, orange lines). This is mainly due to strong cancellation of heat transport between the upward and downward branches of the meridional overturning cell within the tropics [Eq. (8)]. Moving farther equatorward, anomalous cross-equator currents are controlled by an anticlockwise cell at a lag of -4 months (Fig. 12a). The anticlockwise cell becomes much weaker at zero lag, and a clockwise cell south of the equator starts affecting the cross-equator currents at the same time (Fig. 12b). At 4-month lag, the cross-equator currents are fully controlled by the clockwise cell (Fig. 12c). These meridional cells result in baroclinic flows that shift the warm surface water and cold subsurface water in different directions, and thus can affect the cross-equator heat transport via the mass-balanced manner [Eq. (7)]. This process accounts for about $50 \%$ of the regressed cross-equator heat transport in the $0-440-\mathrm{m}$ layer (Fig. 10b, orange line), while the rest is associated with a net volume transport across the equator in that layer (Fig. 10b, red line).
Special attention should be given to the $100-\mathrm{m}$ interface of the tropical ocean where the vertical heat transport associated with zonal cells counteracts that due to the non-mass-balanced component around the El Niño peak (cf. red and blue lines in Fig. 10c). The regression of $\psi_{\text {ZOC }}$ [Eq. (10)] shows a clockwise cell in the Pacific Ocean 4 months prior to the El Niño peak, accompanied by an anticlockwise cell in the Indian Ocean, with the former being 5 times stronger than the latter (Fig. 13a). The regressed zonal cell in the Atlantic Ocean is weaker than $1 \mathrm{~Sv}^{\circ} \mathrm{C}^{-1}$ and therefore is ignored in the following discussion. The clockwise cell in the Pacific Ocean becomes 50\% weaker at the event peak, and there is an anticlockwise cell developing in the eastern Pacific below $250 \mathrm{~m}$ (Fig. 13b), which eventually replaces the clockwise cell at 4-month lags (Fig. 13c). These zonal overturning cells acting on the west-east tilting of isotherms in the Pacific Ocean explain the behavior of the zonal cell component in Fig. 10c in a manner similar to the meridional cell component discussed above. The mean thermocline is almost flat in the Indian Ocean at $100 \mathrm{~m}$ (Fig. 13a, green contour), so 
Regressed meridional overturning stream function $\left(\mathrm{Sv} /{ }^{\circ} \mathrm{C}\right)$
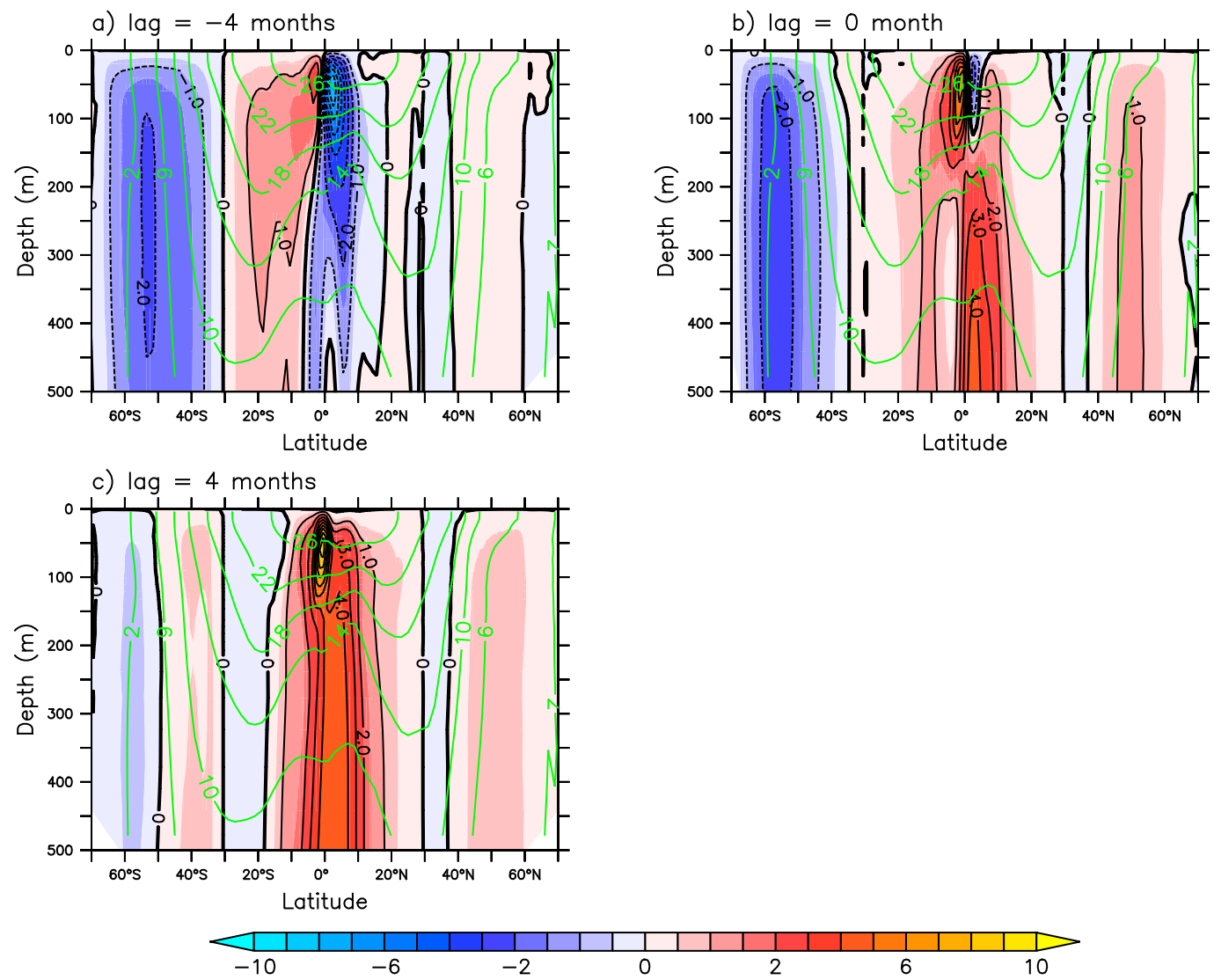

FIG. 12. Regressions of the meridional overturning streamfunction [Eq. (9)] to the N34 index at lags of (a) -4 , (b) 0 , and (c) 4 months $\left(\mathrm{Sv}^{\circ} \mathrm{C}^{-1}\right)$. Positive values indicate clockwise cells, and negative values indicate anticlockwise cells. The zonal average of mean temperature is shown in green contours for reference.

the zonal cell component can only generate very limited vertical heat transport there.

\section{d. Comparison between ECCOv4 and CCSM4}

The use of ECCOv4 implies two caveats in our analyses, in addition to those mentioned in section 2. First, ECCOv4 is an ocean-only model forced by adjusted ERA-Interim reanalysis. This means the atmospheric dynamics and its interaction with the ocean are not included explicitly in ECCOv4. Second, the 20-yr simulation of ECCOv4 (1992-2011) only covers one strong ENSO event and a few moderate ones. The low degrees of freedom thus render large uncertainties in the regression analysis. To address these two deficiencies, we extend the diagnoses to the fully coupled climate model CCSM4 (Gent et al. 2011), which represents the ENSO dynamics reasonably well, such as the delayed/recharge oscillator paradigm (Deser et al. 2012). Monthly data from a 100-yr preindustrial control experiment of CCSM4 are used to examine its heat budget based on Eq. (2). Unlike
ECCOv4, the heat diffusion term is not saved for CCSM4's simulations, so it is not included in the comparison.

In CCSM4, we observe that heat is redistributed into the upper tropical oceans, both meridionally and vertically, before and at the peak of El Niño, whereas it is removed from there after the event peak via the vertical advection (Fig. 14). This result is in good agreement with ECCOv4 (Fig. 8), and the corresponding heat advection is of the same order of magnitude between the two models. In terms of the tropical SHF, it imposes a cooling tendency to the ocean before the El Niño peak in CCSM4, while the opposite is found in ECCOv4. At and after the El Niño peak, consistent heat removal from the ocean via this component is observed between CCSM4 and ECCOv4, with a similar magnitude. Moving to higher latitudes, the SHF anomaly exhibits poor agreement between the two models during ENSO events, but it is consistently weaker than its tropical counterpart in both models. In CCSM4, the full-depth GOHC anomaly reaches its maximum 6 months before the El Niño 
Regressed zonal overturning stream function $\left(\mathrm{Sv} /{ }^{\circ} \mathrm{C}\right) 30 \mathrm{~S}-30 \mathrm{~N}$

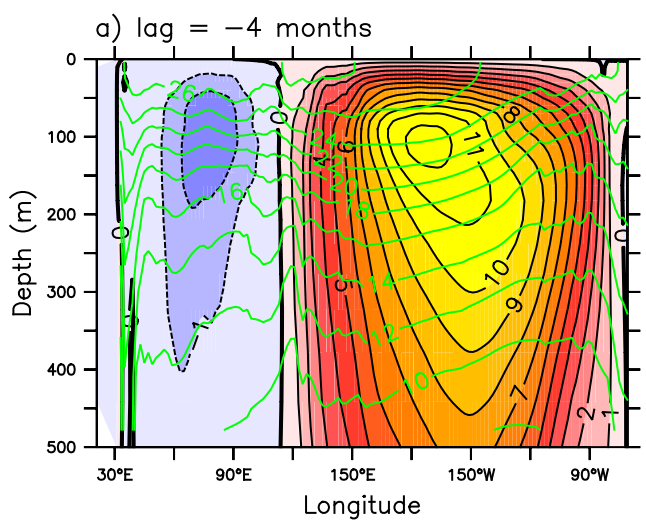

c) $\operatorname{lag}=4$ months

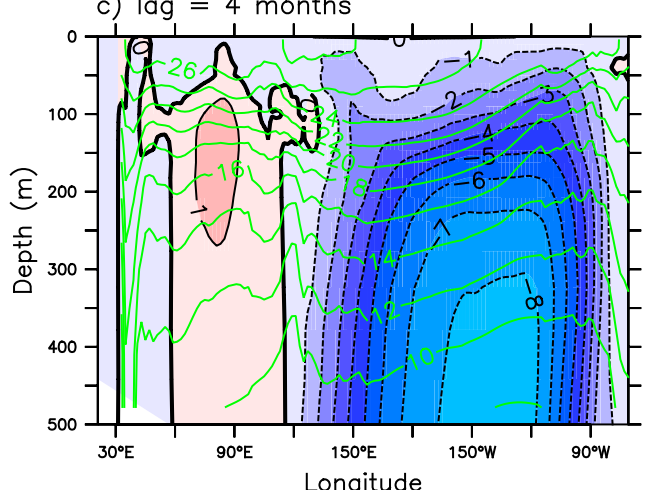

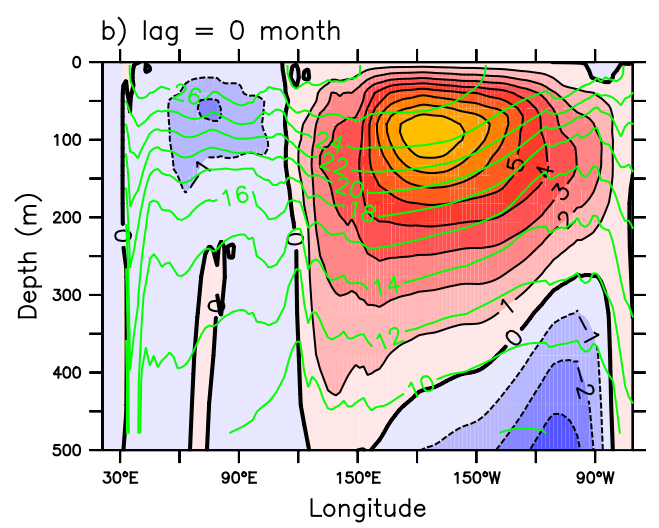

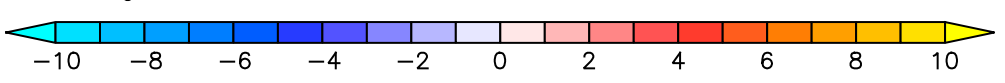

FIG. 13. Regressions of the zonal overturning streamfunction for the tropical Indo-Pacific region [Eq. (10)] to the N34 index at lags of (a) -4 , (b) 0 , and (c) 4 months $\left(\mathrm{Sv}^{\circ} \mathrm{C}^{-1}\right)$. Positive values indicate clockwise cells, and negative values indicate anticlockwise cells. Mean temperature averaged over $30^{\circ} \mathrm{S}-30^{\circ} \mathrm{N}$ is shown in green contours for reference.

peak (not shown), which is different from the in phase relationship suggested in Johnson and Birnbaum (2017).

The general agreement between the results of CCSM4 and ECCOv4 is encouraging as they are of very different model setups. The discrepancies between them could result from different ocean mean states (i.e., preindustrial in CCSM4 vs historical in ECCOv4) but more likely reflect uncertainties in simulating ENSO's global impacts using ocean and climate models. Further investigation of these discrepancies is thus important for improving model's performance on this regard, but this is too ambitious to be addressed here.

\section{Discussion}

Previous work by Mayer et al. (2014) argued that the ENSO-related energy perturbations are mostly confined in the tropical oceans. In contrast, based on the budgetclosed ECCOv4, we found that heat is redistributed into the tropical oceans during El Niño events but removed from there during La Niña events. In this regard, it is necessary to integrate the heat content beyond the tropical oceans when considering the planetary energy budget during ENSO events.

The atmospheric heat transport out of the tropical region some months after the El Niño peak is 60-80 TW per unit N34 change in ERA-Interim (Mayer et al. 2014), which is comparable to the regressed SHF anomaly of $50 \mathrm{TW}^{\circ} \mathrm{C}^{-1}$ in the extratropical region in ECCOv4 (at 4-month lag; Fig. 5d, red line). This implies that the SHF anomaly in the extratropical region might result from anomalous heat redistribution in the atmosphere, which can be further linked to the SST anomalies associated with ENSO events (Klein et al. 1999; Mayer and Haimberger 2012). In other words, the extratropical SHF anomaly is possibly a remote response to anomalous heat content variations in the upper tropical ocean. Future studies with coupled models would be helpful to verify this hypothesis. 
a) Developing phase lag $=-4$ months

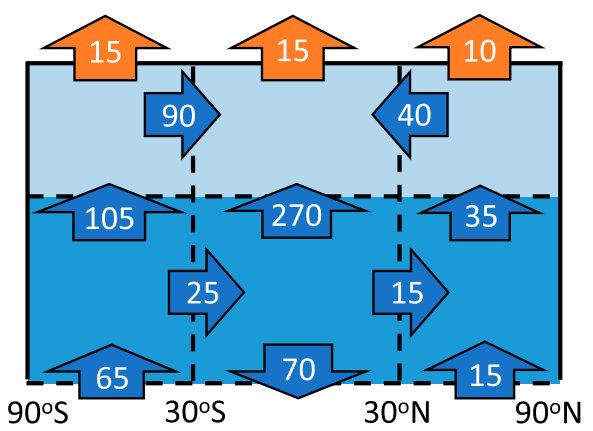

b) Peak phase lag $=0$ month

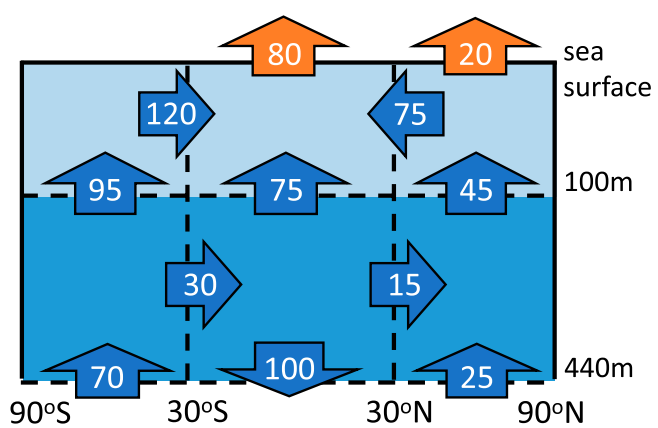

c) Decaying phase lag $=4$ months
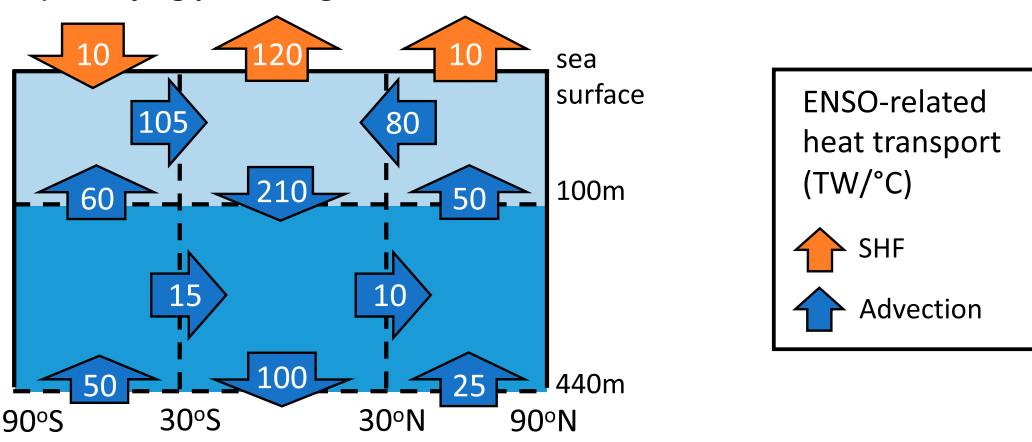

FIG. 14. As in Figs. 8a-c, but derived from a 100-yr preindustrial control simulation of the CCSM4 climate model.

The heat diffusion term is not saved for the simulation of CCSM4 and thus is not included here.

The finding that multiple processes contribute significantly to the anomalous heat exchange across $100 \mathrm{~m}$ motivates an inspection of their regional imprints. Taking the peak phase of El Niño as an example, the regression pattern of $w^{\prime} \bar{\theta}$ is dominated by the tropical Pacific where anomalous heat transports of about $400 \mathrm{~W} \mathrm{~m}^{-2}{ }^{\circ} \mathrm{C}^{-1}$ are observed (Fig. 15a). In contrast, the regression patterns of $\bar{w} \theta^{\prime}, w^{\prime} \theta^{\prime}$, and diffusion are an order smaller than that of $w^{\prime} \bar{\theta}$ in most regions (Figs. 15b-d). This result depicts a seemingly contradictory picture where a single process dominates the regional pattern but multiple processes play a role in determining the global integral. One explanation is the constraint of the volume conservation (i.e., water upwelled to the upper ocean must be subducted back to the deep ocean elsewhere). Therefore, the term $w^{\prime} \bar{\theta}$, despite forming strong regional imprints, can only have a limited impact on the global integral. On the other hand, no such constraint is applied to $\bar{w} \theta^{\prime}, w^{\prime} \theta^{\prime}$, and diffusion terms. Therefore, despite these terms being regionally weak, they can result in nonnegligible contributions to global integrals. Liang et al. (2017) have assessed bidecadal changes in the vertical heat transport using ECCOv4. They found that although the regional patterns of the change mostly come from the heat advection, it is the heat diffusion that contributes to a significant change in the global integral. Both their and our results emphasize that the dominance of oceanic processes depends on the spatial scales of interest.

\section{Summary}

Although ENSO's impact on the global-scale heat content variations has been recognized in the literature, the underlying mechanism was not well understood or adequately quantified. Classical ENSO studies have examined the surface-layer heat balance and the volume budget of warm water (water warmer than $20^{\circ} \mathrm{C}$ ) in great detail for the tropical Pacific Ocean. Similar analyses, however, have barely been extended to higher latitudes or deeper depths that are integrated parts of ENSO's global imprints. Here, to fill this gap and to complement previous ENSO studies, we have examined the ENSOrelated heat exchanges between the tropics and extratropics meridionally and across $100 \mathrm{~m}$ vertically for the global ocean of 0-440-m depth. The use of a dynamically consistent ocean reanalysis allows us to gain new insight into the pathways and physical processes through which 

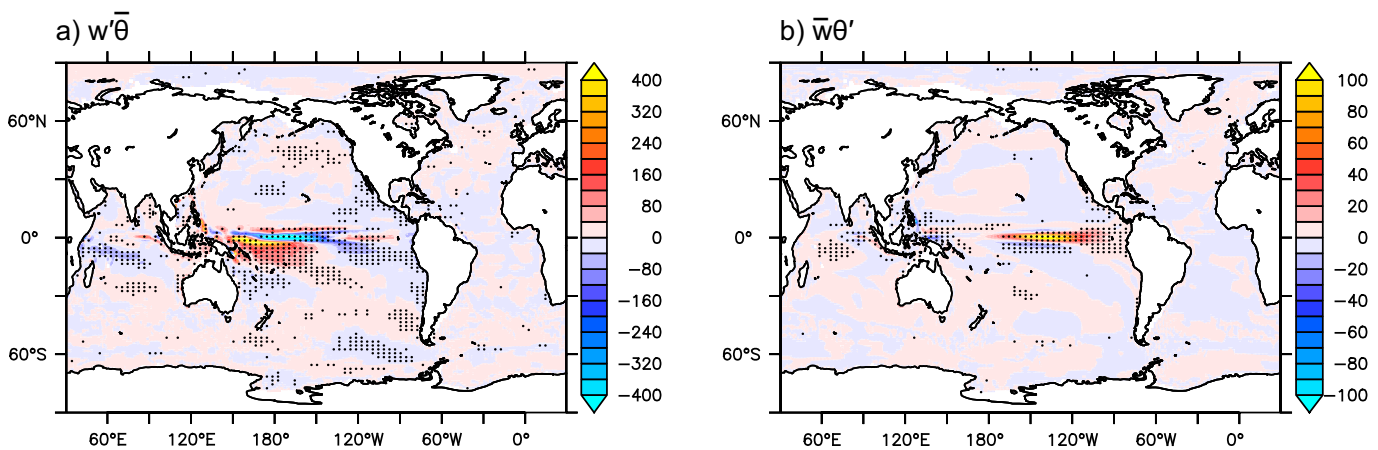

c) $w^{\prime} \theta^{\prime}$

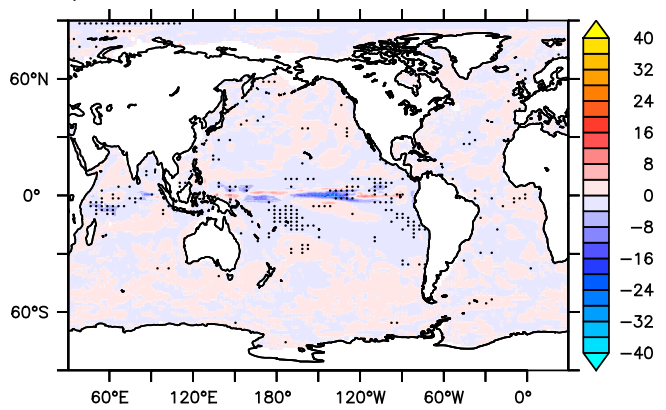

d) diffusion

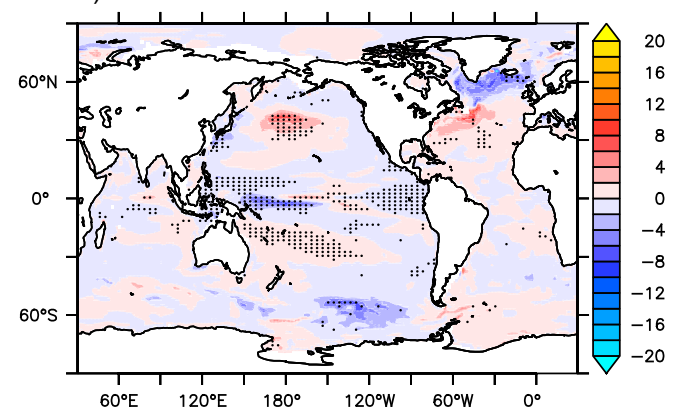

FIG. 15. Regressed vertical heat transports due to (a) $w^{\prime} \bar{\theta}$, (b) $\bar{w} \theta^{\prime}$, (c) $w^{\prime} \theta^{\prime}$, and (d) diffusion terms across $100 \mathrm{~m}$ at the El Niño peak $\left(\mathrm{W} \mathrm{m}^{-2}{ }^{\circ} \mathrm{C}^{-1}\right)$. Positive values indicate upward heat transport. Values significantly different from 0 are denoted by stippling. Note that (b)-(d) have smaller color scales than (a). The results are based on the ECCOv4 product.

anomalous heat exchanges occur. The main findings of this study are summarized below.

During the onset and peak phases of El Niño, heat is brought into the $0-100-\mathrm{m}$ layer in both tropical $\left(30^{\circ} \mathrm{S}-\right.$ $30^{\circ} \mathrm{N}$ ) and extratropical oceans and redistributed equatorward, resulting in heat content build-up in the upper tropical oceans. The heat content build-up tends to trigger a local surface heat flux response in the tropics that is largely responsible for the heat loss of the global ocean at and after the El Niño peak, although this process is partially offset by the surface heat flux in higher latitudes. The large-scale heat redistribution described above from ECCOv4 is consistent with that revealed in the literature (see section 1). The meridional heat convergence over the tropical oceans $\left(30^{\circ} \mathrm{S}-30^{\circ} \mathrm{N}\right)$ during ENSO events is found to be nearly in quadrature to its equatorial $\left(5^{\circ} \mathrm{S}-5^{\circ} \mathrm{N}\right)$ counterpart as described in the recharge oscillator theory (Jin 1997).

The ENSO-related heat redistribution is primarily a result of anomalous advection of mean temperature $\mathbf{v}^{\prime} \bar{\theta}$, except at $100-\mathrm{m}$ depth in the tropics where mean advection of anomalous temperature $\bar{w} \theta^{\prime}$ and nonlinear advection $w^{\prime} \theta^{\prime}$ are as important as $w^{\prime} \bar{\theta}$ for vertical heat exchange. The terms $\bar{w} \theta^{\prime}$ and $w^{\prime} \bar{\theta}$ are integrated over broader meridional extents here, so it is inappropriate to simply refer to them as the thermocline and Ekman feedbacks as in classical ENSO studies. During El Niño events, wind stress anomalies drive a meridional overturning circulation that brings seawater upward in the extratropics but downward in lower latitudes. This circulation acting on the section-averaged temperature, that is, the non-mass-balanced heat transport [Eq. (6)], fully controls the anomalous heat exchange between the tropics and higher latitudes in $0-100 \mathrm{~m}$, and explains part of that exchange between the $0-100-\mathrm{m}$ and $100-440-\mathrm{m}$ ranges in the vertical direction. The rest of the vertical heat exchange is due to anomalous overturning circulations acting on zonal or meridional temperature differences [Eqs. (7) and (8)]. This mechanism is of particular importance in maintaining the heat content build-up in the upper tropical oceans before the El Niño peak.

The global-scale heat budget analysis is extended to the fully coupled climate model CCSM4, in an attempt to address ECCOv4's apparent deficiencies: 1) the lack of a dynamical atmosphere model and 2) short simulation periods. Encouraging agreement is found between ECCOv4 and CCSM4 in terms of the large-scale heat redistribution pathways in the ocean, and the surface heat exchange in the tropics, while discrepancies remain with regard to, for instance, the behavior of the surface heat flux in the extratropics. The two-dimensional heat transport diagram presented here (Fig. 8 ) provides useful 
insight into monitoring the planetary energy budget during ENSO events. The quantitative results of different heat transport processes could serve as a benchmark for evaluating ENSO's imprints in the global and regional heat content in different estimates and help us better understand interannual global variability.

Acknowledgments. We thank the Estimating the Circulation and Climate of the Ocean (ECCO) Consortium for providing the ECCO.v4.r2 product, which can be downloaded from ftp://mit.ecco-group.org/ecco_for_las/version_ 4/release2/. The heat budget analysis is conducted using gcmfaces toolbox written by Gaël Forget (https:/github. com/gaelforget/gcmfaces). Suggestions and comments from Michael McPhaden, Dean Roemmich, Susan Wijffels, and Ming Feng are acknowledged. Q.W. and J.H. were supported by the National Natural Science Foundation of China (41776027) and the National Basic Research Program of China (2015CB954004). X.Z. was supported by Centre for Southern Hemisphere Oceans Research (CSHOR) and the Earth Systems and Climate Change Hub of National Environmental Science Programme. Q.W.'s visiting at CSIRO was funded by the China Scholarship Council (201506310098).

\section{REFERENCES}

Adcroft, A., and J.-M. Campin, 2004: Rescaled height coordinates for accurate representation of free-surface flows in ocean circulation models. Ocean Modell., 7, 269-284, https://doi.org/ 10.1016/j.ocemod.2003.09.003.

Balmaseda, M. A., K. Mogensen, and A. T. Weaver, 2013a: Evaluation of the ECMWF ocean reanalysis system ORAS4. Quart. J. Roy. Meteor. Soc., 139, 1132-1161, https://doi.org/10.1002/qj.2063.

$\longrightarrow$, K. E. Trenberth, and E. Källén, 2013b: Distinctive climate signals in reanalysis of global ocean heat content. Geophys. Res. Lett., 40, 1754-1759, https://doi.org/10.1002/grl.50382.

Brady, E. C., 1994: Interannual variability of meridional heat transport in a numerical model of the upper equatorial Pacific Ocean. J. Phys. Oceanogr., 24, 2675-2694, https://doi.org/ 10.1175/1520-0485(1994)024<2675:IVOMHT>2.0.CO;2.

Bretherton, C. S., M. Widmann, V. P. Dymnikov, J. M. Wallace, and I. Bladé, 1999: The effective number of spatial degrees of freedom of a time-varying field. J. Climate, 12, 1990-2009, https://doi.org/10.1175/1520-0442(1999)012<1990:TENOSD> 2.0.CO;2.

Buckley, M. W., R. M. Ponte, G. Forget, and P. Heimbach, 2014: Low-frequency SST and upper-ocean heat content variability in the North Atlantic. J. Climate, 27, 4996-5018, https://doi.org/ 10.1175/JCLI-D-13-00316.1.

,,--- , and -2015 : Determining the origins of advective heat transport convergence variability in the North Atlantic. J. Climate, 28, 3943-3956, https://doi.org/10.1175/ JCLI-D-14-00579.1.

Campin, J.-M., J. Marshall, and D. Ferreira, 2008: Sea iceocean coupling using a rescaled vertical coordinate $z^{*}$. Ocean Modell., 24, 1-14, https://doi.org/10.1016/ j.ocemod.2008.05.005.
Cazenave, A., H.-B. Dieng, B. Meyssignac, K. von Schuckmann, B. Decharme, and E. Berthier, 2014: The rate of sea-level rise. Nat. Climate Change, 4, 358-361, https://doi.org/10.1038/ nclimate2159.

Chen, X., and K.-K. Tung, 2014: Varying planetary heat sink led to global-warming slowdown and acceleration. Science, 345, 897903, https://doi.org/10.1126/science.1254937.

Cheng, L., K. E. Trenberth, M. D. Palmer, J. Zhu, and J. P. Abraham, 2016: Observed and simulated full-depth ocean heat-content changes for 1970-2005. Ocean Sci., 12, 925-935, https://doi.org/10.5194/os-12-925-2016.

Dee, D. P., and Coauthors, 2011: The ERA-Interim reanalysis: Configuration and performance of the data assimilation system. Quart. J. Roy. Meteor. Soc., 137, 553-597, https://doi.org/ 10.1002/qj.828.

Deser, C., and Coauthors, 2012: ENSO and Pacific decadal variability in the Community Climate System Model version 4. J. Climate, 25, 2622-2651, https://doi.org/10.1175/JCLI-D-11-00301.1.

Domingues, C. M., J. A. Church, N. J. White, P. J. Gleckler, S. E. Wijffels, P. M. Barker, and J. R. Dunn, 2008: Improved estimates of upper-ocean warming and multi-decadal sea-level rise. Nature, 453, 1090-1093, https://doi.org/10.1038/nature07080.

England, M. H., and Coauthors, 2014: Recent intensification of wind-driven circulation in the Pacific and the ongoing warming hiatus. Nat. Climate Change, 4, 222-227, https:// doi.org/10.1038/nclimate2106.

Forget, G., J.-M. Campin, P. Heimbach, C. N. Hill, R. M. Ponte, and C. Wunsch, 2015: ECCO version 4: An integrated framework for non-linear inverse modeling and global ocean state estimation. Geosci. Model Dev., 8, 3071-3104, https://doi.org/10.5194/ gmd-8-3071-2015.

$-,-,-\longrightarrow,-$, $-\longrightarrow, 2016$ : ECCO version 4: second release. https://dspace.mit.edu/handle/1721.1/102062.

Gent, P. R., and J. C. McWilliams, 1990: Isopycnal mixing in ocean circulation models. J. Phys. Oceanogr., 20, 150-155, https:// doi.org/10.1175/1520-0485(1990)020<0150:IMIOCM >2.0.CO;2.

_ , and Coauthors, 2011: The Community Climate System Model version 4. J. Climate, 24, 4973-4991, https://doi.org/ 10.1175/2011JCLI4083.1.

Gregory, J. M., 2000: Vertical heat transports in the ocean and their effect on time-dependent climate change. Climate Dyn., 16, 501-515, https://doi.org/10.1007/s003820000059.

Jin, F.-F., 1997: An equatorial ocean recharge paradigm for ENSO. Part I: Conceptual model. J. Atmos. Sci., 54, 811-829, https:// doi.org/10.1175/1520-0469(1997)054<0811:AEORPF>2.0.CO;2.

_ , and J. D. Neelin, 1993: Modes of interannual tropical oceanatmosphere interaction-A unified view. Part I: Numerical results. J. Atmos. Sci., 50, 3477-3503, https://doi.org/10.1175/ 1520-0469(1993)050<3477:MOITOI>2.0.CO;2.

_ , and S.-I. An, 1999: Thermocline and zonal advective feedbacks within the equatorial ocean recharge oscillator model for ENSO. Geophys. Res. Lett., 26, 2989-2992, https://doi.org/ 10.1029/1999GL002297.

_ S. T. Kim, and L. Bejarano, 2006: A coupled-stability index for ENSO. Geophys. Res. Lett., 33, L23708, https://doi.org/ 10.1029/2006GL027221.

Johnson, G. C., and A. N. Birnbaum, 2017: As El Niño builds, Pacific warm pool expands, ocean gains more heat. Geophys. Res. Lett., 44, 438-445, https://doi.org/10.1002/2016GL071767. , B. M. Sloyan, W. S. Kessler, and K. E. McTaggart, 2002: Direct measurements of upper ocean currents and water properties across the tropical Pacific during the 1990s. Prog. Oceanogr., 52, 31-61, https://doi.org/10.1016/S0079-6611(02)00021-6. 
Katsman, C. A., and G. J. van Oldenborgh, 2011: Tracing the upper ocean's "missing heat." Geophys. Res. Lett., 38, L14610, https://doi.org/10.1029/2011GL048417.

Kim, S.-B., T. Lee, and I. Fukumori, 2007: Mechanisms controlling the interannual variation of mixed layer temperature averaged over the Niño-3 region. J. Climate, 20, 3822-3843, https://doi.org/ 10.1175/JCLI4206.1.

Klein, S. A., B. J. Soden, and N.-C. Lau, 1999: Remote sea surface temperature variations during ENSO: Evidence for a tropical atmospheric bridge. J. Climate, 12, 917-932, https:// doi.org/10.1175/1520-0442(1999)012<0917:RSSTVD>2.0. $\mathrm{CO} ; 2$.

Large, W. G., and S. G. Yeager, 2004: Diurnal to decadal global forcing for ocean and sea-ice models: the data sets and flux climatologies. NCAR Tech. Note NCAR/TN-460+STR, 105 pp., doi:10.5065/D6KK98Q6.

— , G. Danabasoglu, J. C. McWilliams, P. R. Gent, and F. O. Bryan, 2001: Equatorial circulation of a global ocean climate model with anisotropic horizontal viscosity. J. Phys. Oceanogr., 31, 518-536, https://doi.org/10.1175/1520-0485(2001)031<0518: $\mathrm{ECOAGO}>2.0 . \mathrm{CO} ; 2$.

Lee, T., I. Fukumori, and B. Tang, 2004: Temperature advection: Internal versus external processes. J. Phys. Oceanogr., 34, 1936-1944, https://doi.org/10.1175/1520-0485(2004)034<1936: TAIVEP $>2.0 . \mathrm{CO} ; 2$.

Liang, X., and L. Yu, 2016: Variations of the global net air-sea heat flux during the "hiatus" period (2001-10). J. Climate, 29, 36473660, https://doi.org/10.1175/JCLI-D-15-0626.1.

— C. Wunsch, P. Heimbach, and G. Forget, 2015: Vertical redistribution of oceanic heat content. J. Climate, 28, 3821-3833, https://doi.org/10.1175/JCLI-D-14-00550.1.

- C. G. Piecuch, R. M. Ponte, G. Forget, C. Wunsch, and P. Heimbach, 2017: Change of the global ocean vertical heat transport over 1993-2010. J. Climate, 30, 5319-5327, https:// doi.org/10.1175/JCLI-D-16-0569.1.

Loeb, N. G., J. M. Lyman, G. C. Johnson, R. P. Allan, D. R. Doelling, T. Wong, B. J. Soden, and G. L. Stephens, 2012: Observed changes in top-of-the-atmosphere radiation and upper-ocean heating consistent within uncertainty. Nat. Geosci., 5, 110-113, https://doi.org/10.1038/ngeo1375.

Macdonald, A. M., and M. O. Baringer, 2013: Ocean heat transport. Ocean Circulation and Climate: A 21st Century Perspective, S. Gerold et al., Eds., Academic Press, 759-785.

Marshall, J., A. Adcroft, C. N. Hill, L. Perelman, and C. Heisey, 1997: A finite-volume, incompressible Navier Stokes model for studies of the ocean on parallel computers. J. Geophys. Res., 102, 5753-5766, https://doi.org/10.1029/96JC02775.

Mayer, M., and L. Haimberger, 2012: Poleward atmospheric energy transports and their variability as evaluated from ECMWF reanalysis data. J. Climate, 25, 734-752, https://doi.org/10.1175/ JCLI-D-11-00202.1.

__ K. E. Trenberth, L. Haimberger, and J. T. Fasullo, 2013: The response of tropical atmospheric energy budgets to ENSO. J. Climate, 26, 4710-4724, https://doi.org/10.1175/ JCLI-D-12-00681.1.

—_, L. Haimberger, and M. A. Balmaseda, 2014: On the energy exchange between tropical ocean basins related to ENSO. J. Climate, 27, 6393-6403, https://doi.org/10.1175/ JCLI-D-14-00123.1.

McPhaden, M. J., 2012: A 21st century shift in the relationship between ENSO SST and warm water volume anomalies. Geophys. Res. Lett., 39, L09706, https://doi.org/10.1029/ 2012 GL051826.
, S. E. Zebiak, and M. H. Glantz, 2006: ENSO as an integrating concept in Earth science. Science, 314, 1740-1745, https://doi.org/ 10.1126/science. 1132588 .

Meehl, G. A., J. M. Arblaster, J. T. Fasullo, A. Hu, and K. E. Trenberth, 2011: Model-based evidence of deep-ocean heat uptake during surface-temperature hiatus periods. Nat. Climate Change, 1, 360-364, https://doi.org/10.1038/nclimate1229.

Meinen, C. S., 2005: Meridional extent and interannual variability of the Pacific Ocean tropical-subtropical warm water exchange. J. Phys. Oceanogr., 35, 323-335, https://doi.org/ 10.1175/JPO-2694.1.

— volume changes in the equatorial Pacific and their relationship to El Niño and La Niña. J. Climate, 13, 3551-3559, https:// doi.org/10.1175/1520-0442(2000)013<3551:OOWWVC $>2.0$. $\mathrm{CO} ; 2$.

$\longrightarrow$, and — 2001: Interannual variability in warm water volume transports in the equatorial Pacific during 1993-99. J. Phys. Oceanogr., 31, 1324-1345, https://doi.org/10.1175/ 1520-0485(2001)031<1324:IVIWWV>2.0.CO;2.

Picaut, J., M. Ioualalen, C. Menkes, T. Delcroix, and M. J. McPhaden, 1996: Mechanism of the zonal displacements of the Pacific warm pool: Implications for ENSO. Science, 274, 1486-1489, https://doi.org/10.1126/science.274.5292.1486.

_- F. Masia, and Y. du Penhoat, 1997: An advectivereflective conceptual model for the oscillatory nature of the ENSO. Science, 277, 663-666, https://doi.org/10.1126/ science.277.5326.663.

Piecuch, C. G., R. M. Ponte, C. M. Little, M. W. Buckley, and I. Fukumori, 2017: Mechanisms underlying recent decadal changes in subpolar North Atlantic Ocean heat content. J. Geophys. Res. Oceans, 122, 7181-7197, https://doi.org/ 10.1002/2017JC012845.

Rhein, M., and Coauthors, 2013: Observations: Ocean. Climate Change 2013: The Physical Science Basis, T. F. Stocker et al., Eds., Cambridge University Press, 255-315.

Roemmich, D., and J. Gilson, 2011: The global ocean imprint of ENSO. Geophys. Res. Lett., 38, L13606, https://doi.org/ 10.1029/2011GL047992.

_ J. A. Church, J. Gilson, D. P. Monselesan, P. Sutton, and S. E. Wijffels, 2015: Unabated planetary warming and its ocean structure since 2006. Nat. Climate Change, 5, 240-245, https:// doi.org/10.1038/nclimate2513.

Santoso, A., M. J. McPhaden, and W. Cai, 2017: The defining characteristics of ENSO extremes and the strong 2015/2016 El Niño. Rev. Geophys., 55, 1079-1129, https://doi.org/10.1002/ 2017RG000560.

Stammer, D., and Coauthors, 2002: Global ocean circulation during 1992-1997, estimated from ocean observations and a general circulation model. J. Geophys. Res., 107, 3118, https:// doi.org/10.1029/2001JC000888.

, K. Ueyoshi, A. Köhl, W. G. Large, S. A. Josey, and C. Wunsch, 2004: Estimating air-sea fluxes of heat, freshwater, and momentum through global ocean data assimilation. J. Geophys. Res., 109, C05023, https://doi.org/10.1029/ 2003JC002082.

, M. A. Balmaseda, P. Heimbach, A. Köhl, and A. T. Weaver, 2016: Ocean data assimilation in support of climate applications: Status and perspectives. Annu. Rev. Mar. Sci., 8, 491-518, https://doi.org/10.1146/annurev-marine-122414034113.

Sun, D.-Z., and K. E. Trenberth, 1998: Coordinated heat removal from the equatorial Pacific during the 1986-87 El Niño. 
Geophys. Res. Lett., 25, 2659-2662, https://doi.org/10.1029/ 98GL01813.

Trenberth, K. E., J. T. Fasullo, and M. A. Balmaseda, 2014: Earth's energy imbalance. J. Climate, 27, 3129-3144, https://doi.org/ 10.1175/JCLI-D-13-00294.1.

Wang, W., and M. J. McPhaden, 2000: The surface-layer heat balance in the equatorial Pacific Ocean. Part II: Interannual variability. J. Phys. Oceanogr., 30, 2989-3008, https://doi.org/ 10.1175/1520-0485(2001)031<2989:TSLHBI>2.0.CO;2.

, and - 2001: Surface layer temperature balance in the equatorial Pacific during the 1997-98 El Niño and 1998-99 La Niña. J. Climate, 14, 3393-3407, https://doi.org/10.1175/ 1520-0442(2001)014<3393:SLTBIT > 2.0.CO;2.

Wijffels, S., D. Roemmich, D. Monselesan, J. Church, and J. Gilson, 2016: Ocean temperatures chronicle the ongoing warming of Earth. Nat. Climate Change, 6, 116-118, https:// doi.org/10.1038/nclimate2924.

Willis, J. K., D. Roemmich, and B. Cornuelle, 2004: Interannual variability in upper ocean heat content, temperature, and thermosteric expansion on global scales. J. Geophys. Res., 109, C12036, https://doi.org/10.1029/2003JC002260.
Wunsch, C., and P. Heimbach, 2013: Dynamically and kinematically consistent global ocean circulation and ice state estimates. Int. Geophys., 103, 553-579, https://doi.org/10.1016/ B978-0-12-391851-2.00021-0.

Yu, L., and R. A. Weller, 2007: Objectively analyzed air-sea heat fluxes for the global ice-free oceans (1981-2005). Bull. Amer. Meteor. Soc., 88, 527-540, https://doi.org/10.1175/BAMS-88-4-527.

Zebiak, S. E., 1989: Oceanic heat content variability and El Niño cycles. J. Phys. Oceanogr., 19, 475-486, https://doi.org/10.1175/ 1520-0485(1989)019<0475:OHCVAE > 2.0.CO;2.

Zhang, X., and M. J. McPhaden, 2006: Wind stress variations and interannual sea surface temperature anomalies in the eastern equatorial Pacific. J. Climate, 19, 226-241, https://doi.org/ 10.1175/JCLI3618.1.

- , and 2008: Eastern equatorial Pacific forcing of ENSO sea surface temperature anomalies. J. Climate, 21, 6070-6079, https://doi.org/10.1175/2008JCLI2422.1.

_ and _ 2010: Surface layer heat balance in the eastern equatorial Pacific Ocean on interannual time scales: Influence of local versus remote wind forcing. J. Climate, 23, 4375-4394, https://doi.org/10.1175/2010JCLI3469.1. 